\title{
Robustness of Simple Monetary Policy Rules under Model Uncertainty
}

\author{
Andrew Levin, Volker Wieland, and John C. Williams \\ Board of Governors of the Federal Reserve System \\ Washington, DC 20551
}

November 1998

We appreciate the excellent research assistance of Steven Sumner, as well as helpful comments from Flint Brayton, Larry Christiano, David Lindsey, Athanasios Orphanides, David Reifschneider, John Taylor, Robert Tetlow, and participants in the January 1998 NBER Conference on Monetary Policy Rules. The views expressed here are solely the responsibility of the authors, and should not be interpreted as reflecting the views of the Board of Governors of the Federal Reserve System or the views of any other members of its staff. 


\begin{abstract}
$\underline{\text { ABSTRACT }}$
In this paper, we investigate the properties of alternative monetary policy rules using four structural macroeconometric models: the Fuhrer-Moore model, Taylor's Multi-Country Model, the MSR model of Orphanides and Wieland, and the FRB staff model. All four models incorporate the assumptions of rational expectations, short-run nominal inertia, and long-run monetary neutrality, but differ in many other respects (e.g., the dynamics of prices and real expenditures). We compute the output-inflation volatility frontier of each model for alternative specifications of the interest rate rule, subject to an upper bound on nominal interest rate volatility. Our analysis provides strong support for rules in which the first-difference of the federal funds rate responds to the current output gap and the deviation of the one-year average inflation rate from a specified target. In all four models, first-difference rules perform much better than rules of the type proposed by Taylor (1993) and Henderson and McKibbin (1993), in which the level of the federal funds rate responds to the output gap and inflation deviation from target. Furthermore, first-difference rules generate essentially the same policy frontier as more complicated rules (i.e., rules that respond to a larger number of variables and/or additional lags of output and inflation). Finally, this class of rules is robust to model uncertainty, in the sense that a first-difference rule taken from the policy frontier of one model is very close to the policy frontier of each of the other three models. In contrast, more complicated rules are less robust to model uncertainty: rules with additional parameters can be fine-tuned to the dynamics of a specific model, but typically perform poorly in the other models.
\end{abstract}




\section{Introduction}

In the face of uncertainty about the true structure of the economy, policymakers may disagree about the macroeconomic effects of monetary policy and thus about the appropriate policy setting. One approach to resolving this problem is to search for monetary policy rules that work well across a wide range of structural models; that is, rules that are robust to model uncertainty. ${ }^{1}$ In this paper, we investigate the characteristics of policy rules that yield low output and inflation volatility across four different structural macroeconometric models of the U.S. economy: the FRB staff model (cf. Brayton 1997a), the MSR model of Orphanides and Wieland $(1998),{ }^{2}$ the Fuhrer-Moore (1995) model (henceforth referred to as the FM model), and Taylor's (1993b) Multi-Country Model (henceforth TMCM). All four models incorporate the assumptions of rational expectations, short-run nominal inertia, and long-run monetary neutrality, but differ in many other respects (e.g., the dynamics of prices and real expenditures). We compute the inflation-output volatility frontier of each model for alternative specifications of the interest rate rule, subject to an upper bound on nominal interest rate volatility. We then evaluate robustness to model uncertainty by taking the rules that perform well in one model and measuring their performance in each of the other three models.

Our analysis provides strong support for rules in which the first-difference of the federal funds rate responds to the current output gap and the deviation of the one-year average inflation rate from a specified target. First, in all four models, first-difference rules perform much better than rules of the type considered by Taylor (1993) and Henderson and McKibbin (1993), in which the level of the federal funds rate responds to the output gap and inflation deviation from target. Second, more complicated rules (that is, rules that respond to a larger number of variables and/or additional lags of the output gap and inflation) typically generate very small gains in stabilizing output and inflation compared with optimal first-difference rules. A closely related result is that rules involving model-based forecasts generally do not outperform firstdifference rules based on the current output gap and inflation rate, and quite often generate higher variability of output and inflation. Finally, the class of first-difference rules is robust to model uncertainty, in the sense that a first-difference rule taken from the policy frontier of one model is very close to the policy frontier of each of the other three models. In contrast, we find that 
more complicated rules are somewhat less robust to model uncertainty: rules with a larger number of free parameters can be fine-tuned to the dynamics of a specific model, but often perform poorly in other models compared with the best simple rules.

The approach of evaluating policy rules used in this paper follows the long and distinguished tradition dating to Phillips (1954). ${ }^{3}$ As is standard in this literature, we assume the objective of policy is to minimize the weighted sum of the unconditional variances of the inflation rate and the output gap (the percent deviation of GDP from its potential level). In addition, we allow interest rate volatility to enter into the policymakers' optimization problem. The funds rate is set according to a time-invariant policy rule. For a given class of policy rules, the policy frontier traces out the best obtainable outcomes in terms of inflation, output, and funds rate volatility. We refer to the policy rules underlying such a frontier as "optimal" in the sense that these rules represent solutions to the specified constrained optimization problem.

One major difference between our analysis and much of that in the previous literature is that we compute optimal policy frontiers using large rational expectations macroeconomic models-including models with more than 100 equations-as opposed to traditional structural models or small rational expectations models. ${ }^{4}$ Policy rule analysis using traditional models is particularly prone to the Lucas Critique (1976). Fischer (1977) and Phelps and Taylor (1977) made strides in overcoming the inconsistency between policy and expectations inherent in traditional models by using small rational expectations structural models for policy analysis. ${ }^{5}$ In the past, policy rule analysis using rational expectations models was hampered by the computational cost in solving and computing moments of models with more than a small number of equations. Analysis was generally limited to the comparison of a small set of policy regimes as in Bryant (1989), Bryant (1993), and Taylor (1993b). Increases in computer speed and the development of efficient solution algorithms have made the computation of optimal frontiers of large linear rational expectations models feasible.

We present the policy frontiers in inflation-output volatility space, with each curve corresponding to a particular constraint on the volatility of the first-difference of the funds rate. Interest rate volatility plays a key role in our analysis. All four models share the feature of 
a tradeoff between interest rate volatility and inflation-output volatility, even at levels of interest rate volatility significantly above those implied by estimated policy rules or observed in the data. That is, the variability of output and inflation can be reduced by using highly aggressive rules, but such rules also induce wild fluctuations in interest rates. In this paper, we focus our attention on rules that feature relatively moderate levels of interest rate volatility.

One argument for doing so is that the relatively low level of funds rate volatility seen in the data may be a consequence of a preference on the part of policymakers for low interest rate volatility. Even if no fundamental preference for low interest rate volatility exists, two reasons remain to focus on rules that generate moderate levels of interest rate volatility. First, linear policy rules that generate highly volatile interest rates prescribe frequent and large violations of the non-negativity constraint on the federal funds rate. In principle, one could analyze nonlinear rules that incorporate this lower bound on interest rates, but doing so would substantially raise the computational costs of our analysis. ${ }^{6}$ Second, the hypothesized invariance of the estimated model parameters to changes in policy rules is unlikely to hold true under policies that are so dramatically different (in terms of funds rate volatility) from those seen during the sample periods over which the models were estimated.

The outline of the paper is as follows. Section 2 provides a brief description of the four models. Section 3 outlines the objective function and constraints used in determining the policy frontiers of each model, and describes the computational methods used to obtain these frontiers. Section 4 analyzes the inflation-output volatility frontier of each model for the following classes of policy rules: 3-parameter rules in which the funds rate responds to the current output gap, a moving average of the inflation rate, and the lagged funds rate; more complicated rules that incorporate a larger number of observed state variables; and rules that incorporate model-based forecasts of the output gap and inflation rate. This section also considers the extent to which these results are sensitive to the information lags that policymakers typically face. Section 5 analyzes the performance of other simple rules and investigates several potential explanations for the superior performance of rules with a coefficient near unity on the lagged interest rate. Section 6 compares the extent to which simple and complicated rules are robust to model uncertainty. Conclusions then follow. 


\section{Comparison of Basic Model Properties}

This section provides a brief overview of the structure and basic properties of the four models. Table 1 summarizes the basic features of each model, including (1) the level of aggregation for expenditures, prices, employment, and the external sector; (2) the specification of wage and price dynamics; (3) the forward-looking elements of the expenditure block, including the long-term bond maturity and the discount rate used in computing permanent income; and (4) the sample period used in estimating each model. The behavioral equations of the FM model were estimated using FIML, while a combination of OLS, 2SLS, and GMM were used in estimating the parameters of the other three models.

Aggregate Demand. The FM model represents aggregate spending by a single reducedform equation corresponding to an IS curve. The current output gap depends on its lagged values over the past two quarters and the lagged value of the long-term real interest rate, which is defined as a weighted average of ex ante short-term real interest rates with maturity equivalent to a 30-year coupon bond. The parameter estimates are taken from Fuhrer (1997a). The FM model does not explicitly include trade variables or exchange rates; instead, net exports (and the relationship between real interest and real exchange rates) are implicitly incorporated in the IS curve equation.

The MSR model disaggregates real spending into five components: private consumption, fixed investment, inventory investment, net exports, and government purchases. ${ }^{7}$ The aggregate demand components exhibit partial adjustment to their respective equilibrium levels, measured as shares of potential GDP. Equilibrium consumption is a function of permanent income (discounted $10 \%$ per quarter) and the real two-year bond rate, equilibrium fixed investment is a function of output growth and the real bond rate, and equilibrium inventory investment depends only on output growth. Equilibrium government purchases are a constant share of GDP. Net exports are assumed to be fixed in the simulations reported here.

The TMCM model disaggregates IS components further; for example, spending on fixed investment is separated into three components: equipment, nonresidential structures, and residential construction. The specification of these equations is very similar to that of the more aggregated equations in the MSR model. In TMCM, imports follow partial adjustment to an 
equilibrium level that depends on U.S. income and the relative price of imports, while exports display partial adjustment to an equilibrium level that depends on foreign output and the relative price of exports. Uncovered interest rate parity determines each bilateral exchange rate (up to a time-varying risk premium); e.g., the expected one-period-ahead percent change in the DM/\$ exchange rate equals the current difference between U.S. and German short-term interest rates.

The FRB model features about the same level of aggregation as TMCM for private spending but divides government spending into six components, each of which follows a simple reduced-form equation that includes a counter-cyclical term. The specification of most non-trade private spending equations follows Tinsley's (1993) generalized adjustment cost model. Each component has a specific flow or stock equilibrium condition; for example, equilibrium aggregate consumption is proportional to wealth. ${ }^{8}$ Households and businesses adjust their spending in each category according to the solution of a quadratic adjustment cost problem. The resulting spending decision rules are specified as forward-looking error correction equations: the current growth of each spending variable depends on up to three of its own lagged values and on expected future growth in equilibrium spending, and responds negatively to the lagged percent deviation between actual and equilibrium spending levels. Exports and non-oil imports are specified as error-correction processes with long-run income and price elasticities set equal to unity. Uncovered interest rate parity determines the multilateral exchange rate, subject to a sovereign risk premium that moves with the U.S. net external asset position.

Aggregate Supply. In FM, MSR, and TMCM, the aggregate wage rate is determined by overlapping wage contracts. In particular, the aggregate wage is defined to be the weighted average of current and three lagged values of the contract wage rate. TMCM follows the specification in Taylor (1980), where the current nominal contract wage is determined as a weighted average of expected nominal contract wages, adjusted for the expected state of the economy over the life of the contract. FM and MSR use the overlapping real contract wage specification proposed by Buiter and Jewitt $(1981,1989)$ and implemented by Fuhrer and Moore (1995), in which the real contract wage-the contract wage deflated by the aggregate wage-is determined as a weighted average of expected real contract wages, adjusted for the expected average output gap over the life of the contract. ${ }^{9}$ 
In FM and MSR, the aggregate price level is a constant markup over the aggregate wage rate. In contrast, the output price in TMCM follows a backward-looking error-correction specification: current output price inflation depends positively on its own lagged value, on current wage inflation, and on lagged import price inflation, and responds negatively (with a coefficient of -0.2) to the lagged percent deviation of the actual price level from equilibrium. Import prices error-correct slowly to an equilibrium level equal to a constant markup over a weighted average of foreign prices converted to dollars. This partial adjustment of import and output prices imparts somewhat more persistence to output price inflation than would result from staggered nominal wages alone.

The FRB model explicitly models potential output as a function of the labor force, crude energy use, and a composite capital stock, using a three-factor Cobb-Douglas production technology. The equilibrium output price is a markup over a weighted average of the productivity-adjusted wage rate and the domestic energy price. The specification of wage and price dynamics follows the generalized adjustment cost framework used in the FRB IS block. Wage inflation depends on lagged wage inflation over the previous three quarters, as well as expected future growth in prices and productivity, and a weighted average of expected future unemployment rates. Price inflation depends on its own lagged values over the past two quarters, as well as expected future changes in equilibrium prices and expected future unemployment rates. In addition, both wages and prices error-correct to their respective equilibrium levels. As in the other models, a vertical long-run Phillips curve is imposed in estimation.

Unlike the other three models, the FRB model contains a detailed accounting of various categories of income, taxes, and stocks, an explicit treatment of labor markets, and endogenous determination of potential output. Long-run equilibrium in the FRB model is of the stock-flow type; the income tax rate and real exchange rate risk premium adjust over time to bring government and foreign debt-to-GDP ratios back to specified (constant) levels.

Foreign Sector. Neither FM nor MSR explicitly include foreign variables; in contrast, both TMCM and the full FRB staff model include detailed treatments of foreign variables. TMCM features estimated equations for demand components and wages and prices for the other G-7 countries at about the level of aggregation of the U.S. sector. The full FRB staff model 
includes a total of 12 sectors (countries or regions) which encompass the entire global economy. Because of the size of the model, the cost of solving and computing the moments of the full FRB model is prohibitive. Preliminary investigations using TMCM suggest that the characteristics of optimal U.S. monetary policies are not greatly affected by the precise specification of the foreign sector; the details of these results are described in the Appendix. ${ }^{10}$ Based on these results and the benefits of reduced computational cost, we replaced the full set of equations describing foreign countries in the FRB staff model with two simple reduced form equations for foreign output and prices. For the remainder of the paper, we refer to this simplified version of the model as the FRB model. ${ }^{11}$

Dynamic Properties. We now turn to the basic dynamic properties of output and inflation-as measured by the unconditional autocorrelations-in the four models. Because output and inflation dynamics are sensitive to the specification of monetary policy, we begin by specifying a baseline monetary policy rule. For this purpose, we use the following interest rate reaction function, which was estimated using quarterly U.S. data over the sample period 1980Q1 to 1996Q4:

$$
\begin{aligned}
& \mathbf{r}_{t}=-0.0042+0.795 \mathbf{r}_{t-1}+0.625 \pi_{t}+1.171 \mathbf{y}_{t}-0.967 \mathbf{y}_{t-1}+\mathbf{u}_{t} \\
& \begin{array}{lllll}
(0.0036) & (0.07) & (0.13) & (0.26) & (0.23)
\end{array} \\
& \bar{R}^{2}=0.925 ; \text { S.E.R. }=0.010 ; D W=2.50
\end{aligned}
$$

where $\mathbf{r}_{\mathrm{t}}$ is the federal funds rate, $\boldsymbol{\pi}_{\mathrm{t}}$ is the four-quarter moving average of the inflation rate, and $\mathbf{y}_{\mathrm{t}}$ is the current output gap. ${ }^{12}$ Clarida, Gali and Gertler (1998) and others argue that this period was characterized by a fairly stable policy regime that differed substantially from that of the 1960s and 1970s. This estimated policy rule features a relatively large coefficient on the lagged funds rate and a fairly aggressive response to increases in inflation and output gaps. Furthermore, the pattern of coefficients on the output gap and its lag suggest that policy not only responded to the level of output but also its recent growth. 
Given this interest rate reaction function, we compute the dynamic properties of each model using the solution methods described in Section 3 below. The inflation autocorrelogram of each model under the estimated policy rule is depicted in the upper panel of Figure $\mathbf{1}^{13}$ Inflation is highly persistent in the FM and MSR models, a feature of the overlapping real wage contract that Fuhrer and Moore (1995) have emphasized. The FRB model exhibits somewhat less inflation persistence, but by far the least degree of inflation persistence is found in TMCM, in which the inflation autocorrelogram falls below zero after only four quarters. Even when combined with some inertia in price markups, the staggered nominal wage contract specification in TMCM delivers relatively low inflation persistence.

The lower panel of Figure 1 depicts the output gap autocorrelogram of each model. In the FM model, the output gap is extremely persistent and displays some "over-shooting" in that the autocorrelation turns negative after five years. The FRB model output gap displays considerably less persistence and slightly more over-shooting than the FM model. The MSR and TMCM models-based on similar aggregate demand specifications-share the feature of a relatively low degree of output gap persistence, although it is slightly higher in the MSR model because the monetary policy response to inflation causes some of the persistence in inflation to spill over to output.

To provide a more detailed comparison of the dynamic properties of aggregate demand across models, it is useful to consider the following regression equation:

$$
\Delta \mathbf{y}_{t}=-\delta \mathbf{y}_{t-1}+\theta \Delta \mathbf{y}_{t-1}-\phi\left(\mathbf{r}_{t-1}-\mathrm{E}_{t-1} \pi_{t}\right)+\varepsilon_{t}
$$

where $\mathbf{r}_{\mathrm{t}-1}-\mathrm{E}_{\mathrm{t}-1} \pi_{\mathrm{t}}$ is the lagged value of the ex ante real federal funds rate. The parameter $\delta$ indicates the degree of persistence (speed of error-correction) of the output gap; the parameter $\theta$ indicates the extent to which the output gap exhibits a short-run accelerator effect; and the parameter $\phi$ indicates the sensitivity of aggregate demand to a change in the short-term real interest rate. We use this simple specification to compare the basic properties of output dynamics between the models and to the data.

Table 2 indicates the asymptotic values of $\delta, \theta$, and $\phi$ for each model computed using the unconditional moments of each model and the estimated coefficients and standard errors 
obtained from fitting equation (2) using U.S. data over the sample period 1966Q1 - 1995Q4. Although the MSR model and TMCM have roughly similar output autocorrelograms, the table shows that these models actually imply very different behavior for the output gap. In particular, the output gap in TMCM error-corrects to zero rapidly and displays essentially no accelerator effect, whereas the output gap in the MSR model error-corrects more gradually and displays a strong accelerator effect. The FM and FRB models both imply a relatively high degree of persistence, while the accelerator effect in FM is nearly twice as strong as in the FRB model. Finally, the coefficients on the real short-term interest rate are similar across the four models, with FM displaying the least real interest rate sensitivity of output.

\section{Computing Policy Frontiers}

In this section, we indicate the methods used to solve each model and obtain its unconditional moments for a specific interest rate rule. Then we specify the objective function and constraints faced by the monetary policymaker, and we describe the methods used to obtain the optimal parameter values in each model for a given functional form of the interest rate rule.

Analyzing a Specific Rule. Our analysis incorporates a wide variety of interest rate rules, in which the federal funds rate may depend on its own lagged values as well as the current, lagged, and expected future values of other model variables. In general, the interest rate rule can be expressed as follows:

$$
\mathbf{r}_{t}=\sum_{j=1}^{l} H_{j}^{1} \mathbf{r}_{t-j}+\sum_{j=1}^{m} H_{j}^{2} \underset{t}{E \mathbf{z}_{t+j}}+\sum_{j=0}^{n} H_{j}^{3} \mathbf{z}_{t-j}
$$

where $\mathbf{r}_{\mathrm{t}}$ is the federal funds rate, and the vector $\mathbf{z}$ is a set of model variables that enter the interest rate reaction function. The lagged funds rate coefficients are given by $H_{j}^{1} \quad(j=1$ to $l)$, while the coefficients on other model variables are given by the vectors $H_{j}^{2} \quad\left(j=1\right.$ to $m$ ) and $H_{j}^{3}$ (j=0 to $n$ ). Henceforth we will refer to the combined set of coefficients by the vector $H=\left\{H^{1}\right.$, $H^{2}, H^{3}$ \}. After discussing how to compute the moments of each model for a specific value of $H$, 
we will consider the problem of determining the optimal value of $H$ for a given choice of the elements of $\mathbf{z}$ and the lead and lag orders $l, m$, and $n$.

As in Fuhrer (1997), we analyze the performance of a specified policy rule in each model by computing the reduced form representation of the saddle point solution and then evaluating an analytic expression for the unconditional second moments of the model variables. For linear models, this approach yields accurate results far more efficiently than simulation-based methods. To take advantage of these methods, we have constructed a linearized version of TMCM and a log-linear version of the FRB model; however, these approximations have negligible effects on the relevant dynamic properties of the two models.

Thus, each of the four models can be written in the following form:

$$
\sum_{j=1}^{M} A_{j} E \mathbf{x}_{t+j}+\sum_{j=0}^{N} B_{j} \mathbf{x}_{t-j}+C \mathbf{e}_{t}=0
$$

where $\mathbf{x}$ is the vector of all model variables, and $\mathbf{e}$ is a vector of serially uncorrelated disturbances with mean zero and finite covariance matrix $\boldsymbol{\Omega}$. The interest rate reaction function comprises a single row of equation (4), while the remaining rows contain the structural equations of the model. Thus, the parameters of the interest rate rule are contained in one row of the coefficient matrices $A_{j}$ ( $j=1$ to $\left.M\right)$ and $B_{j}(j=0$ to $N)$, while this row of $C$ is identically equal to zero.

We compute the unique stationary rational expectations solution to equation (4) using the Anderson and Moore (1985) implementation of the Blanchard and Kahn (1980) method, modified to take advantage of sparse matrix functions. ${ }^{14}$ The reduced form of this solution can be expressed as follows:

$$
\mathbf{x}_{t}=\sum_{j=1}^{N} D_{j}(H) \mathbf{x}_{t-j}+F(H) \mathbf{e}_{t}
$$

where the reduced-form coefficient matrices $D_{j}(j=1$ to $K)$ and $F$ depend on the monetary policy parameters $H$ as well as the structural parameters of the model. By defining the 
vector $\widetilde{\mathbf{x}}_{\mathbf{t}}=\left(\mathbf{x}_{\mathbf{t}-\mathbf{1}}, \ldots, \mathbf{x}_{\mathbf{t}-\mathbf{K}}\right)^{\prime}$, we can express this solution in companion form:

$$
\widetilde{\mathbf{x}}_{\mathbf{t}}=P(H) \tilde{\mathbf{x}}_{\mathbf{t}-1}+Q(H) \mathbf{e}_{\mathbf{t}}
$$

Then the unconditional contemporaneous covariance matrix for $\widetilde{\mathbf{x}}_{\mathbf{t}}$, denoted by $V_{\mathrm{o}}$, is given by:

$$
V_{o}=\sum_{j=0}^{\infty} P^{j} Q \Omega Q^{\prime} P^{j}
$$

Using the implicit expression $V_{\mathrm{o}}=P V_{\mathrm{o}} P^{\prime}+Q \Omega Q^{\prime}$, we compute $V_{\mathrm{o}}$ iteratively using the doubling algorithm described in Hansen and Sargent (1997), modified to take advantage of sparse matrix functions. Given $V_{\mathrm{o}}$, the autocovariance matrices of $\tilde{\mathbf{x}}_{\mathbf{t}}$ are readily computed using the relationship $V_{j}=P^{j} V_{\mathrm{o}}$.

The Optimization Problem. For a given functional form of the interest rate rule, we assume that the interest rate rule is chosen to solve the following optimization problem:

$$
\begin{array}{ll}
\underset{H}{\operatorname{Min}} & \lambda \operatorname{Var}\left(\mathbf{y}_{t}\right)+(1-\lambda) \operatorname{Var}\left(\pi_{t}\right) \\
\text { s.t. } & \widetilde{\mathbf{x}}_{t}=P(H) \tilde{\mathbf{x}}_{t-1}+Q(H) \mathbf{e}_{t} \\
& \operatorname{Var}\left(\Delta \mathbf{r}_{t}\right) \leq \boldsymbol{k}^{2}
\end{array}
$$

where $\mathbf{y}_{\mathrm{t}}$ indicates the output gap, $\boldsymbol{\pi}_{\mathrm{t}}$ indicates the four-quarter average inflation rate, and $\operatorname{Var}(\mathbf{s})$ indicates the unconditional variance of variable $\mathbf{s}$. The weight $\lambda \in[0,1]$ reflects the policymaker's preference for minimizing output volatility relative to inflation volatility. We constrain the level of interest rate volatility by imposing the upper bound $\boldsymbol{k}$ on the standard deviation of the first-difference of the federal funds rate; as discussed below, the benchmark value of $\boldsymbol{k}$ is set equal to the funds rate volatility under the estimated policy rule given in 
equation (1). Finally, throughout our analysis, we only consider policy rules that generate a unique stationary rational expectations solution.

To compute the policy frontier of each model for a particular functional form of the interest rate rule, we determine the parameters of this rule which maximize the objective function for each value of $\lambda$ over the range zero to unity. Thus, for a given form of the interest rate rule, the policy frontier of each model traces out the best obtainable combinations of output and inflation volatility, subject to the upper bound on funds rate volatility. This approach differs slightly from that commonly found in the literature, in which interest rate volatility is incorporated into the objective function and each policy frontier is drawn using a different weight on interest rate volatility. The standard approach combines information about model-imposed constraints on policy with policymakers' preferences regarding funds rate volatility, whereas we prefer to maintain a strict distinction between the policymaker's preferences and the constraints implied by the model.

To obtain a benchmark value of $\boldsymbol{k}$ for each model, we obtain the rational expectations solution generated by the estimated policy rule in equation (1), and then we compute the standard deviation of the one-quarter change in the funds rate associated with this rule. It should be noted that this benchmark value of $\boldsymbol{k}$ differs across the four models, in part because each model has been estimated over a different sample period and as a result generates a different amount of funds rate volatility for the same policy rule. For example, the moments for the FRB and TMCM models depend in part on shocks from the 1970's-a period of substantial economic turbulence-while the shocks for the FM and MSR models are from the relatively tranquil 1980's and early 1990's. Henceforth, when we construct a policy frontier subject to the benchmark constraint that funds rate volatility does not exceed that of the estimated rule, we refer to the resulting policy frontier as an $E$-frontier.

For a particular functional form of the interest rate rule, we determine the policy frontier by solving the optimization problem in equation (8) for a range of values of the objective function weight $\lambda$. For a given value of $\lambda$, we start with an initial guess for the rule parameters, obtain the reduced-form solution matrices $G$ and $H$, compute the unconditional moments, and 
calculate the value of the objective function; then a hill-climbing algorithm is applied which iteratively updates the parameter vector until an optimum is obtained.

Thus, to determine a single policy frontier, it is necessary to compute hundreds or even thousands of rational expectations solutions at alternative values of the policy rule parameters. Given our objective of performing a systematic analysis of policy frontiers for a wide range of functional forms of the interest rate rule, it is essential to make use of the highly efficient solution algorithms outlined above. On a Sun Ultra Enterprise 3000 computer-about as fast as an Intel Pentium II 300 Mhz computer-only a few CPU seconds are needed to solve and compute the moments of a small-scale model like FM or MSR, while solving a large-scale macroeconometric model like TMCM or the FRB model requires about five CPU minutes.

\section{Policy Frontiers for Simple and Complicated Rules}

In this section, we analyze the properties of policy frontiers for several alternative specifications: rules in which the federal funds rate responds to only three variables (the current output gap, a moving average of the inflation rate, and the lagged funds rate), more complicated rules that incorporate a larger number of observed state variables, and rules that incorporate model-based forecasts of the output gap and inflation rate. Finally, we consider the extent to which these results are sensitive to a one-quarter information delay.

Simple Policy Rules. We start by considering 3-parameter rules in which the federal funds rate $\mathbf{r}_{\mathrm{t}}$ is determined as a linear function of the current output gap, $\mathbf{y}_{\mathrm{t}}$, the four-quarter average inflation rate, $\pi_{\mathrm{t}}$, and the lagged funds rate, $\mathbf{r}_{\mathrm{t}-1}$ :

$$
\mathbf{r}_{t}=\rho \mathbf{r}_{t-1}+(1-\rho)\left(\mathbf{r}^{*}+\pi_{t}\right)+\alpha\left(\pi_{t}-\pi^{*}\right)+\beta \mathbf{y}_{t}
$$

where $\mathbf{r}^{*}$ is the unconditional mean of the equilibrium real interest rate and $\pi^{*}$ is the inflation target (both assumed to be constant throughout this paper). ${ }^{15}$

The solid lines in Figure 2 depict the 3-parameter $E$-frontier of each model. As expected, the frontier is convex to the origin, with truncated vertical and horizontal asymptotes as the objective function in equation (8) switches from exclusive concern about stabilizing inflation 
$(\lambda=0)$ toward exclusive concern about stabilizing output $(\lambda=1)$. Because we restrict attention to policy rules that generate a unique stationary rational expectations equilibrium, the unconditional variance of inflation is finite even in the case where $\lambda=1$.

Each panel of Figure 2 also indicates the relative performance of the estimated rule, denoted by the letter $\boldsymbol{E}$. Because the estimated rule generates the same amount of funds rate volatility as the 3-parameter $E$-frontier of each model, comparison of the estimated rule to the policy frontier is straightforward. The estimated rule performs appreciably worse than the optimal 3-parameter rules for MSR, FRB, and TMCM, despite the fact that the estimated rule incorporates an additional variable (the lagged output gap). As discussed below, the optimal value of $\boldsymbol{\rho}$ for these three models is substantially higher than the estimated value of about 0.8 shown in equation (1).

The coefficient values for optimal 3-parameter rules are shown in Figure 3. In each model, a lower inflation coefficient generates a higher standard deviation of inflation, as one would expect. The output gap coefficients vary noticeably less along each policy frontier. The output gap coefficients for MSR are close to unity along the whole policy frontier. In the FRB model, the output gap coefficient is smaller for rules corresponding to low values of $\lambda$, but is otherwise quite close to unity. The output gap coefficient in TMCM ranges between 0.6 and 1.5 along the policy frontier. Finally, the optimal output gap and inflation coefficients for the FM model are much smaller than for the other three models.

The key result to be noted from Figure 3 is that the 3-parameter policy frontiers of all four models are associated with rules in which the coefficient $\boldsymbol{\rho}$ on the lagged funds rate is very close to unity. In particular, the parameter $\rho$ takes values in the range of $\{0.84,0.95\}$ for the FM model; $\{1.0,1.1\}$ for the MSR model; $\{0.92,1.03\}$ for the FRB model; and $\{0.94,0.98\}$ for TMCM. Thus, as noted above, the relatively poor performance of the estimated reaction function in the latter three models can be attributed mainly to the fact that the estimated value of $\rho=0.8$ in equation (1) is substantially smaller than the optimal value of $\boldsymbol{\rho}$ for these models.

To examine this feature more closely, we consider the class of first-difference rules, which are a special case of the 3-parameter rules described by the previous equation: 


$$
\mathbf{r}_{t}=\mathbf{r}_{t-1}+\alpha\left(\pi_{t}-\pi^{*}\right)+\beta \mathbf{y}_{t}
$$

For three of the four models (MSR, FRB, and TMCM), the E-frontier for first-difference rules is virtually identical to the 3-parameter $E$-frontier; i.e., imposing the constraint $\boldsymbol{\rho}=1$ is essentially costless in these models. For the FM model, first-difference rules are associated with slightly higher output and inflation volatility compared with 3-parameter rules, as seen by comparing the dashed and solid lines in the upper-left panel of Figure 2.

Finally, the lower-left panel of Figure 2 shows that stabilization performance deteriorates substantially in the FRB model if the simple policy rule is expressed in terms of the one-quarter inflation rate rather than four-quarter average inflation rate. In all four models, policy rules that incorporate the four-quarter average inflation rate are strictly preferred to alternative rules that utilize a higher-frequency measure of the inflation rate. ${ }^{16}$ The one-quarter inflation rate contains a substantial amount of high-frequency noise that is essentially unforecastable and immune to stabilization efforts; the four-quarter average inflation rate filters out some of this noise.

Complicated Policy Rules. In the simple rules described by equations (4) and (5), the funds rate is adjusted in response to only three variables: the current output gap, the fourquarter average inflation rate, and the lagged interest rate. In practice, central banks have access to far more information about the state of the economy. Optimal control theory suggests that the policy rule should incorporate all relevant information, that is, the rule should involve all of the state variables of the specific economic model under consideration. Thus, we investigate the extent to which complicated rules that respond to expanded subsets of the state variables can generate substantially lower output and inflation volatility.

Due to computational costs, our analysis of this issue focuses on the two smaller models, FM and MSR, for which we can obtain policy frontiers for rules that include all observed state variables. The FM model contains eight such variables (the lagged interest rate, the current values of the output gap and one-quarter inflation rate, two lags of the output gap, and three lags of the one-quarter inflation rate), while the MSR model contains 20 observed state variables. We have also investigated rules with up to six parameters in the FRB model and TMCM; the results of those experiments confirm the findings reported here for the two smaller models. 
For the FM model, we find that the optimal 8-parameter rules put substantial weight on one or both of the lagged output terms that are excluded from the 3-parameter policy rules. Furthermore, the optimal 8-parameter rules typically exhibit complicated patterns of weights on the current and lagged one-quarter inflation rates, whereas these weights are constrained to be equal in the 3-parameter policy rules (which only respond to the four-quarter average inflation rate). Evidently, the optimal 8-parameter rules are fine-tuned to the model, in the sense that the pattern of coefficients on lagged output and inflation reflects the dynamic properties of the FM model. Nevertheless, as seen in the top panel of Figure 4, the 8-parameter policy frontier is nearly indistinguishable from the 3-parameter policy frontier; that is, more complicated rules provide only negligible improvements in output and inflation stability beyond that achieved by optimal simple rules.

Because demand is disaggregated into four components in the MSR model, additional gains in performance might be expected by augmenting the 3-parameter rule in equation (9) to allow policy to respond differently to consumption, fixed investment, inventory investment, and government spending. Thus, we consider 12-parameter rules which include current values of these four components of aggregate demand as well as the variables in the 8-parameter rules described above. Unsurprisingly, the optimal 12-parameter rules exhibit complicated coefficient patterns that are fine-tuned to the dynamics of the model. The lower panel of figure 4 shows that these complicated 12-parameter rules yield visible but not striking improvements in output and inflation stability compared with simple 3-parameter rules. Augmenting the 12-parameter rule with other observed state variables (that is, the lagged values of the individual components of aggregate demand) yields trivial improvements in the policy frontier.

We conclude from this analysis that small improvements in output and inflation stability may be possible by including more variables (i.e., more information about the state of the economy) in the interest rate rule. Of course, such benefits may be offset by the lower degree of transparency associated with complicated policy rules. Furthermore, Section 6 considers the implications of model uncertainty and provides evidence that complicated policy rules are somewhat less robust than optimal simple rules. 


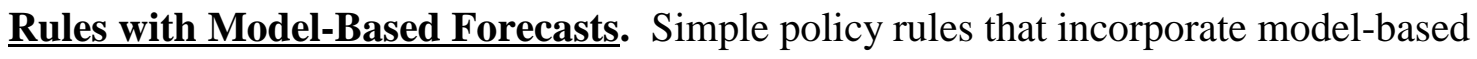
forecasts of the output gap and inflation rate implicitly respond to all the observed states in the model (albeit in a highly restricted fashion) but are relatively parsimonious in terms of the number of free parameters in the rule. We have already noted that small reductions in output and inflation volatility can be obtained using complicated rules that respond to a large number of observed state variables. We now analyze the extent to which these performance gains can be achieved by simple rules that incorporate forecasts of the output gap and inflation rate. In this analysis, we assume the forecasts are model-consistent and are known to the public.

Using three different approaches to incorporating model-based forecasts of the output gap and inflation rate, we find negligible benefits from using model-based forecasts rather than realized values of these variables. First, when we augment the class of 3-parameter rules to allow policy to respond additionally to one-quarter and two-quarter forecasts of the output gap and/or the inflation rate, we find very little improvement in performance relative to optimal 3-parameter rules based only on current and lagged variables. Second, we consider 3-parameter rules in which the current output gap is replaced by model-based forecasts of the future output gap at various horizons. In all four models, rules that respond to the current output gap stabilize output and inflation just as effectively as rules that respond to model-based forecasts of the output gap. Finally, we consider 3-parameter rules which replace the current four-quarter average inflation rate with a model-based forecast of this inflation rate, at a forecast horizon of one to four quarters. For the FM and MSR models, using a model-based inflation forecast always results in worse performance than using the current inflation rate. For TMCM and the FRB model, using the two-quarter-ahead model-based inflation forecast generates a very small improvement in performance compared with using the current inflation rate.

Information Lags. In the preceding analysis, we have side-stepped one potentially important issue: policymakers may not have full knowledge of the current state of the economy, but instead must act upon data that comes in with a lag of weeks, months, or even longer. As McCallum (1997) has emphasized, policy rules must be operational in the sense that they can be implemented in real time. In this paper, we do not examine the implications of using mismeasured data, but instead focus on the impact of information lags. ${ }^{17}$ 
A one-quarter information lag probably provides an accurate representation of the time delay with which information becomes available to policymakers. The first "advance" release of quarterly NIPA data occurs within one month of the end of the quarter, and monthly labor market and consumer price index (CPI) data are available by the middle of the following month. Other weekly and monthly data become available with short lags. To make the contrast to the results based on complete current information as stark as possible, we restrict ourselves to policies that depend only on lagged inflation, output gaps, and interest rates. We do not consider rules that incorporate current-quarter forecasts based on lagged information; if anything, our approach introduces an additional upward bias in assessing the true costs associated with information lags.

Figure 5 compares the 3-parameter policy frontiers using current and lagged variables. The imposition of lagged variables in the rule imposes miniscule costs in terms of stabilization in the FM and FRB models, and relatively small costs in the MSR and TMCM models. The characteristics of well-performing rules are also essentially unchanged. Evidently, a one-quarter information lag does not inhibit effective inflation and output stabilization in the models we consider here.

The reason for these small costs is that inflation and output are highly persistent in all four models and thus the lagged inflation rate and lagged output gap are good proxies for the current values of these variables. Nevertheless, the degree of output persistence does vary across the four models and largely accounts for the differences in the costs of information lags. For the MSR and TMCM models, which display relatively low output persistence (first-order autocorrelation under first-difference rules of about 0.75 and 0.5 , respectively), the cost of using lagged output gaps is larger than for the FM and FRB models with relatively high output persistence ( 0.95 and 0.85 first-order autocorrelations under first-difference rules, respectively). In the case of inflation, any effects on performance due to the use of lagged variables is further dampened by the fact that rules on the 3-parameter policy frontier involve the four-quarter average inflation rate. The marginal impact of the current inflation rate is thus relatively small, so the shift in timing has little effect on the stabilization properties of rules on the policy frontier. 


\section{Comparison of Alternative Simple Rules}

In this section, we focus in greater detail on the properties of 3-parameter rules of the form given in equation (9). This class of policy rules nests "level" rules such as those considered by Henderson and McKibbin (1993) and Taylor (1993), in which the lagged funds rate coefficient $\boldsymbol{\rho}=0$. We shall use the term "interest rate smoothing" to refer to rules in which this coefficient is substantially larger than zero, as in partial adjustment rules $(0<\boldsymbol{\rho}<1)$ and firstdifference rules $(\boldsymbol{\rho}=1){ }^{18}$ As shown previously in Figure 3, the optimal value of $\boldsymbol{\rho}$ even exceeds unity in certain cases, but is never quite as large as the optimal values obtained by Rotemberg and Woodford (1997). Of course, level rules are also associated with persistence in the funds rate, because output and inflation exhibit substantial persistence in all four models.

Table 3 indicates the values of $\boldsymbol{\alpha}, \boldsymbol{\beta}$, and $\boldsymbol{\rho}$ for eight different rules in this class. Rules $\boldsymbol{A}$ and $\boldsymbol{B}$ are taken from the $E$-frontier of the FRB model, with the value of $\boldsymbol{\rho}$ constrained to unity. These rules correspond to values of $\lambda=1 / 4$ and $\lambda=3 / 4$, respectively (i.e., the weight on output volatility relative to inflation volatility) in the objective function given in equation (8). The two rules labelled $\boldsymbol{C}$ and $\boldsymbol{D}$ are more aggressive rules that stabilize output and inflation more effectively than rules $\boldsymbol{A}$ and $\boldsymbol{B}$ but induce substantially higher interest rate volatility. ${ }^{19}$ Rule $\boldsymbol{T}$ is the rule proposed by Taylor (1993a). Rule $\mathbf{T 2}$ is a modified version of Taylor's rule in which the coefficient on the output gap has been doubled. Rules $\boldsymbol{V}$ and $\boldsymbol{W}$ are optimal policy rules for the dynamic general equilibrium model analyzed by Rotemberg and Woodford (1997).

Table 4 clearly shows that rules $\boldsymbol{T}$ and $\boldsymbol{T} 2$, in which the level of the funds rate responds to the output gap and inflation rate, are dominated by rules like $\boldsymbol{A}$ and $\boldsymbol{B}$, where the first-difference of the funds rate responds to the output gap and inflation rate. Rules $\boldsymbol{V}$ and $\boldsymbol{W}$ perform relatively poorly in stabilizing output and inflation in all four models. One reason for these poor results is that rules $\boldsymbol{V}$ and $\boldsymbol{W}$ set $\boldsymbol{\rho}$ to about 1.3, which is much larger than the optimal range of about 0.9 to 1.1 for the four models considered here. Furthermore, even if policymakers only care about stabilizing inflation (i.e., $\lambda=0$ ), the output gap coefficient should generally be larger than the values of 0.06 and 0.08 used in rules $\boldsymbol{V}$ and $\boldsymbol{W}$, respectively, because the current output gap is an important leading indicator for the inflation rate. 
Figure 6 provides further information on the benefits of a large coefficient on the lagged funds rate in comparison with level rules. The dotted line indicates the $E$-frontier associated with level rules; i.e., the inflation-output volatility frontier for rules having the form of equation (9) with $\boldsymbol{\rho}=0$, under the constraint that the standard deviation of $\Delta \mathbf{r}$ does not exceed that generated by the estimated rule in equation (1). The solid and dashed lines show the $E$-frontiers for 3-parameter rules and first-difference rules, as previously depicted in Figure 2. As previously noted, the $E$-frontiers for 3-parameter rules and first-difference rules are virtually identical for three of the models, while the optimal 3-parameter rules associated with the FM model incorporate values of $\boldsymbol{\rho}$ which are large but noticeably smaller than unity.

Figure 6 reveals very substantial gains from setting $\boldsymbol{\rho}$ near unity in all four models. In fact, these are the largest gains we have found among all the permutations of simple policy rules that we have investigated. ${ }^{20}$ In the FRB model, for example, using a first-difference rule instead of a level rule can reduce the standard deviation of output by a full percentage point.

Although empirical evidence reveals a pattern of interest rate smoothing in many industrial countries and is a property of the estimated U.S. interest rate rule in equation (1), the normative case for interest rate smoothing has remained much less clear. ${ }^{21}$ Lowe and Ellis (1997) have recently surveyed the literature and summarized several considerations that tend to favor interest rate smoothing. ${ }^{22}$ One argument, advanced by Goodfriend (1991) and others, is particularly relevant to our analysis. For a given movement in the short-term interest rate, the impact on long-term interest rates is greater if the movement is expected to be sustained rather than short-lived. Thus, interest rate smoothing offers the potential for greater control over long-term bond rates and hence over aggregate demand and inflation.

This rationale for interest rate smoothing is explicitly captured in the four rational expectations models considered here: in each model, monetary policy stabilizes output and inflation mainly through its influence on the long-term real interest rate, which is determined as a weighted average of current and expected future short-term rates. ${ }^{23}$ For a given set of economic conditions, movements in the federal funds rate are expected to persist longer under the first-difference rule compared to the level rule; thus, a given initial adjustment of the federal 
funds rate induces a larger movement in the long-term bond rate and thereby achieves more rapid stabilization of output and inflation.

To evaluate the role of this mechanism in explaining the superior performance of rules with a large coefficient on the lagged funds rate, we conduct counterfactual experiments in each of the two smaller models, FM and MSR. In particular, we shorten the maturity of the term structure equation, and compute new constrained output/inflation volatility frontiers based on rules with three parameters. In the FM model, we replace the 30-year bond rate with the current short-term rate in the IS curve. ${ }^{24}$ We find that the range of values of $\boldsymbol{\rho}$ along the frontier declines from [0.85,0.95] to [0.56,0.8]. In the MSR model, we replace the eight-quarter maturity bond with the current funds rate in the consumption and investment equations and find that the range of coefficients on the lagged federal funds rate along the frontier declines from $[1.0,1.1]$ to $[0.75,1.0]$. Thus, in both models, the optimal coefficient on the lagged funds rate is significantly reduced when the maturity of the relevant long rate is shortened.

In addition to the forward-looking characteristics of long-term bond rates, it is useful to consider several other factors that may contribute to the superior performance of rules with a large coefficient on the lagged funds rate. First, control theory suggests that the optimal policy rule should take into account all available information, including lagged values of the output gap and inflation rate. A rule with a high value of $\boldsymbol{\rho}$ implicitly makes the current interest rate depend on the complete history of output and inflation, albeit in a very restricted way. Thus, the lagged funds rate may be serving as a simple proxy that permits additional information to be included in a suboptimal level rule.

We test this explanation by computing frontiers for rules that include all observable state variables, and then checking whether these complicated rules are characterized by smaller lagged funds rate coefficients. Because of the high computational cost in conducting this experiment, we focus on the small models, FM and MSR. The policy frontiers associated with complicated rules for these models have already been shown in Figure 4. Here we simply note that rules which include all observed state variables call for somewhat smaller coefficients on the lagged funds rate. In the FM model, the range of values of $\rho$ along the frontier is almost identical for the case of three-parameter rules as for rules that respond to all observable state variables, while 
in the MSR model, the range of values of $\boldsymbol{\rho}$ decline from $[1.0,1.1]$ to $[0.9,1.0]$ for rules that respond to all observed state variables.

Next, we consider the relationship between the optimal value of $\boldsymbol{\rho}$ and the preference for funds rate volatility implicitly imposed in drawing the frontiers. For each model, Figure 7 shows three frontiers with different restrictions on funds rate volatility. In each case the baseline $E$-frontier is shown as a solid line. Using frontier rules as a guide, the stabilization gains from increased funds rate volatility are evidently rather small. Table 5 shows typical values of the standard deviation of the level of the funds rate generated by the policies that underlie the frontiers shown in the figure. In each case, outcomes corresponding to the baseline $E$-frontier are given in the first two columns. Except for the MSR model, relaxing the constraint on funds rate volatility much beyond that implied by the $E$-frontier entails so much volatility of the level of the funds rate that the optimal policy rule would regularly dictate negative nominal interest rates when the steady-state nominal interest rate-that is, the sum of the steady-state real interest rate and the target inflation rate-is reasonably low.

In all four models, relaxing the constraint on interest rate volatility results in smaller values of $\boldsymbol{\rho}$ for the 3-parameter rules on the policy frontier. However, the quantitative results differ somewhat across models. In the FM model, the reduction in $\boldsymbol{\rho}$ is particularly pronounced: doubling the upper bound on $\operatorname{SD}(\Delta \mathbf{r})$ causes the range of values for $\boldsymbol{\rho}$ to drop from $[0.85,0.95]$ to $[0.75,0.92]$. In the other three models, relaxing the funds rate volatility constraint leads to somewhat smaller reductions in the optimal value of $\boldsymbol{\rho}$. In the FRB model, doubling $\mathrm{SD}(\Delta \mathbf{r})$ reduces the optimal value of $\rho$ by about 0.07 on average, from a range of $[0.96,1.02]$ to $[0.93,0.96]$. In TMCM and in MSR, doubling $\mathrm{SD}(\Delta \mathbf{r})$ only reduces the optimal value of $\boldsymbol{\rho}$ by about 0.03 . Evidently, even with relatively high interest rate volatility, a relatively large coefficient on the lagged funds rate is preferred in these models.

Finally, we consider the extent to which interest rate rules with a large coefficient on the lagged funds rate stabilize the economy by generating secondary cycles, e.g., overshooting of output. To highlight this feature, we analyse the dynamic response of output to an exogenous increase in aggregate demand under a level rule versus a 3-parameter rule with a high coefficient on the lagged funds rate. Each rule corresponds to the policy frontier associated with the same 
level of interest volatility as that resulting from the estimated rule in equation (1). In the FM model, we consider a one standard deviation shock to the IS curve. In the MSR model, autonomous demand increases due to one-standard-deviation shocks to consumption, fixed investment, inventory investment, and government spending.

Figure 8 shows the stark contrast in the dynamic response of output under the two rules. In each model, the optimal 3-parameter rule substantially dampens the response of output in the first few quarters compared to the optimal level rule and subsequently pushes output below potential for some time. Because the spending equations in both FM and MSR are forwardlooking, these expected future movements in output, prices, and short-term interest rates play a role in dampening the initial impact of the aggregate demand shock. Given the objective of minimizing the variance of output and inflation, there is a potential gain from reducing the peak response at the cost of increasing the extent of overshooting. In both models, moderate overshooting resulting from policy with large values of $\boldsymbol{\rho}$ is preferred to a monotone reversion to equilibrium values; for example, the optimal 3-parameter rule reduces the standard deviation of output by 15 percent in FM and by nearly 40 percent in MSR, compared with the level rule.

In summary, our results suggest that the forward-looking feature of long-term bond rates is the principal explanation for the superior performance of rules in which the lagged funds rate coefficient $\boldsymbol{\rho}$ is near unity. In response to a shock, such an "interest rate smoothing" rule typically generates a small but persistent movement in the short rate, which induces a large movement in the current long-term bond rate and thereby facilitates the stabilization of output and inflation. If we relax the interest rate volatility constraint or expand the set of observed state variables in the policy rule, we observe small reductions in the optimal value of $\boldsymbol{\rho}$, but our conclusions about the advantages of interest rate smoothing are not substantially affected. Finally, we find that interest rate smoothing reduces the variance of output by inducing secondary cycles, which reduce the initial impact of shocks due to the forward-looking nature of aggregate demand. 


\section{Robustness to Model Uncertainty}

To evaluate the extent to which simple policy rules are robust to model uncertainty, we take first-difference rules from the policy frontier of one model, and evaluate the performance of these rules in each of the other three models. In particular, we consider the first-difference rules $\boldsymbol{A}$ and $\boldsymbol{B}$ from the corresponding policy frontier of the FRB model; the parameter values for these rules are given in Table 3. In the FRB model, both rules generate the same standard deviation of the first-difference of the funds rate as that generated by the estimated rule given in equation (1). For each of the other models, we calculate the funds rate volatility associated with each of the two rules, and then we compute a separate policy frontier for each upper bound on funds rate volatility, using the class of 3-parameter rules given by equation (9). For example, the "Rule A" policy frontier for the MSR model is the 3-parameter policy frontier for rules with the same funds rate volatility that rule $\boldsymbol{A}$ generates in this model. For the FM model, rules $\boldsymbol{A}$ and $\boldsymbol{B}$ produce virtually identical amounts of funds rate volatility.

The results of this analysis are depicted in Figure 9, which shows that rules $\boldsymbol{A}$ and $\boldsymbol{B}$ provide reasonably efficient performance in stabilizing output and inflation in all four models. Conditional on the level of interest rate volatility implied by these rules, the coefficients of the rules are such that inflation and output volatility lie very near the 3-parameter policy frontiers of all models. Evidently, in terms of efficiently reducing the volatility of output and inflation, well-chosen simple rules are very robust to the type of model uncertainty encompassed by these four models. Note that this comparison is constructed holding interest rate volatility fixed at the level generated by rule $\boldsymbol{A}$ or $\boldsymbol{B}$. Nevertheless, while these results show that rules $\boldsymbol{A}$ and $\boldsymbol{B}$ are reasonably efficient, this figure does not indicate how well the rules perform in terms of specific values of $\boldsymbol{\lambda}$.

Table 6 reports several summary statistics about the extent to which rules $\boldsymbol{A}$ and $\boldsymbol{B}$ are robust to model uncertainty. The fourth column reports the value of the objective function using the "true" value of $\boldsymbol{\lambda}$ (assumed to be 0.25 for rule $\boldsymbol{A}$ and 0.75 for rule $\boldsymbol{B}$, which are the values used to determine these rules in the FRB model). ${ }^{25}$ The fifth column reports the absolute loss in terms of the objective function implied by following the specified rule $(\boldsymbol{A}$ or $\boldsymbol{B})$ instead of 
the three-parameter optimal rule (with the same amount of interest rate volatility) for the specified value of $\boldsymbol{\lambda}$. The last column reports the value of $\boldsymbol{\lambda}$ which would be consistent with the choice of rule $\boldsymbol{A}$ or $\boldsymbol{B}$ for the particular model; e.g., in the first row, the implicit value of $\lambda=0.1$ means that policymakers with preferences described by $\lambda=0.1$ would choose rule $A$ in the FM model.

These results indicate that if a policymaker were to use the FRB model to choose a policy rule, but the real world were actually described by one of the other three models, the policy rule would generate slightly greater output volatility and slightly less inflation volatility compared with the preferences of the policymaker. In particular, the implicit values of $\boldsymbol{\lambda}$ associated with rules $\boldsymbol{A}$ and $\boldsymbol{B}$ are all smaller in the non-FRB models than the "true" values used in choosing rules $\boldsymbol{A}$ and $\boldsymbol{B}$ in the FRB model. However, while rules $\boldsymbol{A}$ and $\boldsymbol{B}$ are suboptimal, the loss in terms of the objective function, measured either in absolute or percentage terms, is quite small in the MSR model and in TMCM. The somewhat larger loss in the FM model occurs because the optimal 3-parameter rule for that model uses a coefficient below unity on the lagged funds rate.

Now we consider the extent to which complicated rules are robust to model uncertainty. In particular, we take two complicated rules (denoted by $\boldsymbol{P}$ and $\boldsymbol{Q}$ ) from the 12-parameter $E$-frontier of the MSR model, and determine the performance of these rules in the FRB model and in TMCM. Because rules $\boldsymbol{P}$ and $\boldsymbol{Q}$ cannot be implemented directly in the FM model (which does not explicitly treat the components of aggregate demand), we also take two rules (denoted by $\boldsymbol{R}$ and $\boldsymbol{S}$ ) from the 8-parameter $E$-frontier of the MSR model and evaluate the performance of these rules in the FM model. As above, the output and inflation variability of the complicated rules should be compared with simple rules that generate the same level of interest rate volatility. Thus, for each model, we calculate the funds rate volatility associated with each of the two complicated rules, and then we compute a separate policy frontier for each upper bound on funds rate volatility, using the class of 3-parameter rules given by equation (4).

As shown in the left panels of Figure 10, the more complicated rules lie fairly close to the 3-parameter policy frontiers of the FM and FRB models. In TMCM, however, the two 12-parameter rules are much less effective in stabilizing output and inflation than the optimal 3-parameter rules. Thus, while small improvements in output and inflation variability may be 
obtained by using complicated policy rules, these rules are somewhat less robust to model uncertainty compared with simple rules. As discussed in Section 2, the dynamic properties of output and inflation differ substantially across the four models. Thus, it is not very surprising that fine-tuning a complicated rule to one particular model may not be appropriate when policymakers are concerned about model uncertainty.

\section{Conclusions}

This paper has investigated the performance of policy rules across four structural macroeconomic models with rational expectations. Although the four models differ in many important respects (e.g., the level of aggregation, the specification of output and price dynamics, and the treatment of the foreign sector), the characteristics of effective policy rules are essentially the same. To stabilize inflation and output at reasonably low levels of interest rate volatility, the policy rule should respond to the current output gap and to a smoothed measure of inflation, and should incorporate a high degree of interest rate smoothing, that is, a coefficient near unity on the lagged funds rate. These results are essentially unchanged even if the policy rule is restricted to react to output and inflation data from the previous rather than the current quarter.

Interest rate smoothing provides the largest gains from any of the permutations of simple policy rules that we have investigated. Several factors contribute to this result: (i) smooth changes in the short-term interest rate provide control over long-term interest rates and thereby over aggregate demand and inflation at low cost in terms of funds rate volatility; (ii) constraining interest rate volatility as we do in constructing the frontiers favors interest rate smoothing; (iii) the lagged interest rate provides a measure of the existing state of the economy in models with output and inflation persistence; and (iv) with a very high degree of smoothing, such as that associated with first-difference rules, output tends to exhibit "overshooting", which is preferable to returning monotonically to potential under the variance criterion employed here.

Simple rules derived from one model perform very well in the other three models; i.e., these rules are robust to model uncertainty within this class of models. For a given model, complicated rules perform only slightly better than simple ones, even when all observed state variables are incorporated in the rule. Furthermore, these rules are somewhat less robust 
to model uncertainty compared with well-chosen simple rules. Thus, fine-tuning a complicated policy rule to one specific model may not be advisable, because policymakers are faced with substantial uncertainty about the true structure of the economy as well as with competing views about the quantitative effects of alternative policy actions.

Finally, rules that incorporate forecasts of the output gap and inflation rate generally do not outperform optimal rules based on current and lagged variables. This result is related to that regarding complicated rules: even in large models with hundreds of state variables, three variables (the current output gap, a moving average of current and lagged inflation rates, and the lagged funds rate) summarize nearly all the information relevant to setting the federal funds rate efficiently. 


\section{Appendix: US. Monetary Policy under Alternative Foreign Policy Regimes}

Our initial results indicate that within a fairly wide range of alternative foreign monetary policy assumptions (e.g., fixed money growth, interest rate rules), the specific foreign monetary policy regime appear to have only minor implications for the properties of a U.S. monetary policy rule. For example, consider the class of rules in which the first-difference of the federal funds rate responds to the current output gap and inflation deviation from target.

Table 7 provides information about the U.S. inflation-output volatility frontier under two alternative assumptions about foreign monetary policy: (a) each foreign G-7 country follows a fixed money growth rule; or (b) France, Germany, Italy, and the U.K. belong to a monetary union in which the European Central Bank adjusts interest rates in response to the European average output gap and average inflation deviation from target, while Canada and Japan independently follow similar rules. Table 7 shows that in TMCM, neither the position of the U.S. inflationoutput volatility frontier nor the coefficients of rules on the policy frontier are sensitive to this choice of foreign monetary policy assumptions. Impulse response functions generated using the full FRB staff model (cf. Levin et al. 1997) yield similar conclusions.

Based on these results, the results in this paper are based on a smaller version of the FRB staff model, referred to as the FRB model. In this model, foreign output, prices, ex ante long-term real interest rates, and the oil import price deflator are generated by simple autoregressive processes. The trade-weighted real exchange rate is determined by the differential between U.S. and foreign ex ante long-term real interest rates, with an endogenous risk premium that ensures a stable ratio of net external debt to nominal GDP. 


\section{NOTES}

1. We use the term "model uncertainty" to refer to lack of knowledge about which model among a given set of alternatives provides the best description of the economy. For a particular model, we treat the estimated parameters as known with certainty. A small literature exists on the problem of conducting monetary policy under model uncertainty (Karakitsos and Rustem 1984; Becker et al. 1986; Frankel and Rockett 1988; Holtham and Hughes-Hallett 1992; and Christodoulakis et al. 1993). Optimal policy under parameter uncertainty was investigated in the seminal paper of Brainard (1967), and was extended by the work of Kendrick (1982) and others; the more recent literature includes Balvers and Cosimano (1993) and Wieland (1996b, 1998).

2. MSR is a small macroeconometric model of the U.S. economy from 1980 to 1996, developed and used for research on monetary policy rules in the Monetary Studies Section at the Federal Reserve Board (e.g., Orphanides et al. 1997).

3. The literature on policy evaluation using traditional structural models is large and includes important contributions by Cooper and Fischer (1977) and Poole (1970). In recent papers, Fair and Howrey (1996), Ball (1997), and Rudebusch and Svensson (1998) derive optimal policies from traditional structural macroeconomic models.

4. Williams (1997) compares the characteristics of optimal policies under rational expectations and alternative assumptions regarding expectations formation using the FRB staff model.

5. Taylor (1979) and, more recently, Fuhrer (1997a), Svensson (1997a), and Tetlow and von zur Muehlen (1997), derive optimal policies in small rational expectations structural macroeconomic models.

6. This nonlinearity has been investigated in the FM, MSR, and FRB models. Fuhrer and Madigan (1997) conducted deterministic simulations of the Fuhrer-Moore model to assess the extent to which the zero bound prevents real rates from falling and thus cushioning aggregate output in response to negative spending shocks. Orphanides and Wieland (1998) perform stochastic simulations of the MSR model and find that (i) the effectiveness of monetary policy is significantly reduced at inflation targets below 1 percent; and (ii) distortions due to the zero bound generate a non-vertical long run Phillips curve and result in higher inflation and output variability. Reifschneider and Williams (1998) find that under standard linear policy rules, the zero bound begins to reduce stabilization performance in the FRB model for inflation targets below 2 percent; however, by modifying these rules to account for the non-negativity constraint on the federal funds rate, the performance deterioration due to the zero bound can be nearly eliminated, even for a zero inflation target.

7. The demand side of this model is similar to Taylor (1993a) and Taylor and Williams (1993), while the wage-price sector is taken from Fuhrer (1997b). 
8. The consumption equations are based on the life-cycle theory and include different marginal propensities to consume out of different categories of wealth (labor income, property income, stock market) reflecting the differing characteristics of the owners of these assets. See Brayton (1997b) for a discussion.

9. For the FM model, we use the estimated parameters from Fuhrer (1997a). The MSR model uses the parameter estimates of Fuhrer (1997b), for which the implied response of inflation to output gaps is smaller than that obtained by Fuhrer and Moore (1995) and substantially larger than that of Fuhrer (1997a).

10. For example, using TMCM, we computed optimal policies under two alternative assumptions regarding foreign monetary policies. In the baseline case, each foreign country is assumed to follow an independent constant growth rule for money; in the alternative case, the EU countries are assumed to follow a single currency policy described by a Taylor (1994) rule and Canada and Japan follow independent policies using the same Taylor rule specification. The optimal U.S. policy rules were almost identical across the two cases.

11. This version of the model is typically referred to as FRB/US, while the full model is referred to as FRB/GLOBAL.

12. Inflation is measured using the chain-weighted GDP deflator and the output gap is based on estimates of potential output supplied by the Congressional Budget Office. This rule forms part of the MSR model and is taken from Orphanides and Wieland (1998)

13. Throughout the paper, inflation refers to the growth in the GDP price level for FM, MSR, and TMCM, and that of the personal consumption price index for FRB.

14. Sumner and Williams (1998) discuss methods to improve the computational efficiency of algorithms to solve linear rational expectations models.

15. Because we ignore the non-negativity constraint on nominal interest rates, we implicitly assume that the inflation target is sufficiently high so that its effects are muted (cf. footnote 6).

16. In this paper, we focus on rules in which the inflation variable is defined as the 4-quarter average inflation rate. In fact, for the FM, MSR, and FRB models, using an even lowerfrequency measure of the inflation rate (e.g., the 8-quarter or 12-quarter average inflation rate) provides small improvement in terms of the best obtainable outcomes for output and inflation volatility, while the 4-quarter average inflation rate works best in TMCM. However, it should be emphasized that the results of this paper are not sensitive to the choice between a 4-quarter, 8-quarter, or 12-quarter inflation rate in the policy rule. 
17. Sources of mismeasurement relevant for policy rules include the noise in the data due to sampling and data imputation methods and imprecise estimation of potential output and the natural rate of unemployment. Orphanides (1997) studies the relevance of measurement problems for policy rules. Wieland (1997) examines optimal policy when the natural rate is unknown.

18. In the existing literature (e.g., Lowe and Ellis 1997; Goodhart 1998), the phrase "interest rate smoothing" has been used to refer to two different (albeit related) characteristics of interest rate behavior: (i) the degree of persistence in interest rates that results from partial adjustment or error-correction specifications of the interest rate reaction function; and (ii) a policy preference for reducing the variance of short-term interest rates. Throughout this paper, we use the phrase "interest rate smoothing" to refer to policy rules in which the partial adjustment parameter $\rho$ is significantly greater than zero, and avoid using the phrase to refer to rules that generate relatively low interest rate volatility.

19. Rules $\boldsymbol{C}$ and $\boldsymbol{D}$ are included here to maintain consistency with the specifications used by other authors in this volume; these are the rules labeled I and II, respectively, in Table 1 of the Introduction by John B. Taylor. The parameters of rules $\boldsymbol{C}$ and $\boldsymbol{D}$ were originally chosen based on a specification of the 3-parameter rule that incorporated the 12-quarter average inflation rate instead of the 4-quarter average inflation rate. However, rules $\boldsymbol{C}$ and $\boldsymbol{D}$ yield results that are very similar to those of rules $\boldsymbol{A}$ and $\boldsymbol{B}$, respectively.

20. The beneficial impact of interest rate smoothing extends to models that fall outside the class of models we consider here, such as the models in Woodford and Rotemberg (1997) and Rebelo and Xie (1997), that explicitly incorporate optimizing behavior of representative agents.

21. Clarida, Gali and Gertler (1998) also document the practice of interest rate smoothing for U.S. monetary policy.

22. For example, policymakers may dislike frequent reversals in interest rates, either because such changes make the policymaker look poorly informed and undermine confidence in the central bank as argued by Caplin and Leahy (1997), or because it is difficult to obtain broadbased political support for such changes in direction as suggested by Goodhart (1996). Furthermore, by avoiding large movements in interest rates the central bank can reduce financial market volatility and in doing so reduces the likelihood of instability when particular institutions incur large losses. Finally, the nature of the decision-making process may lead to caution. For example, Alan Blinder (1995), when Vice-Chairman of the Board of Governors, argued that uncertainty that policymakers have about the parameters of the underlying model justifies "stodginess" in monetary policy.

23. TMCM and FRB also include an explicit exchange rate channel of monetary policy, while FRB includes a channel for wealth, which is negatively related to long-term real interest rates. 
24. We reduced the coefficient on the real rate to avoid increasing the interest sensitivity of aggregate demand.

25. To normalize the comparison of policy rules, these calculations assume that the value of $\mathbf{k}$ (the upper bound on funds rate volatility) for each model is given by the standard deviation of the funds rate resulting from rule $\boldsymbol{A}$ or $\boldsymbol{B}$. 


\section{REFERENCES}

Anderson, Gary S. 1997. A Reliable and Computationally Efficient Algorithm for Imposing the Saddle Point Property in Dynamic Models. Manuscript, Board of Governors of the Federal Reserve System.

and George R. Moore. 1985. A Linear Algebraic Procedure For Solving Linear Perfect Foresight Models. Economics Letters 17:247-52.

Ball, Laurence. 1997. Efficient Rules for Monetary Policy. NBER Working Paper No. 5952.

Balvers, Ronald and Thomas Cosimano. 1994. Inflation Variability and Gradualist Monetary Policy. Review of Economic Studies 61:721-738.

Becker, R.G., B. Dwolatzky, E. Karakitsos and B. Rustem. 1986. The Simultaneous Use of Rival Models in Policy Optimisation. Economic Journal 96:425-448.

Blinder, Allan. 1995. Central Banking in Theory and Practice, Lecture 1: Targets, Instruments and Stabilisation. Marshall Lecture presented at the University of Cambridge.

Brainard, William. 1967. Uncertainty and the Effectiveness of Policy. American Economic Review 57:411-425.

Brayton, Flint, Andrew Levin, Ralph W. Tryon, and John C. Williams. 1997a. The Evolution of Macro Models at the Federal Reserve Board. Carnegie-Rochester Conference Series on Public Policy 42:115-167.

, Eileen Mauskopf, David Reifschneider, Peter Tinsley, and John Williams. 1997b. The Role of Expectations in the FRB/US Macroeconomic Model. Federal Reserve Bulletin $83: 227-245$.

Bryant, Ralph C., David A. Currie, Jacob A. Frenkel, Paul R. Masson, and Richard Portes. 1989. Macroeconomic Policies in an Interdependent World. Washington, DC: International Monetary Fund.

, Peter Hooper, and Catherine L. Mann. 1993. Evaluating Policy Regimes: New Research in Empirical Macroeconomics. Washington, DC: Brookings Institution.

Buiter, Willem H. and Ian Jewitt. 1981. Staggered Wage Setting with Real Wage Relativities: Variations on a Theme of Taylor. The Manchester School 49:211-228. 
Buiter, Willem H. and Ian Jewitt. 1989. Staggered Wage Setting with Real Wage Relativities: Variations on a Theme of Taylor. In Macroeconomic Theory and Stabilization Policy, ed. Willem H. Buiter. Manchester: Manchester University Press.

Caplin Andrew and John Leahy. 1996. Monetary Policy as a Process of Search. American Economic Review 86:689-702.

Christiano, Lawrence, Martin Eichenbaum, and Christopher Gust. 1997. Interest Rate Smoothing in an Equilibrium Business Cycle Model. Manuscript, Northwestern University.

Christodoulakis, Nico, David Kemball-Cook, and Paul Levine. 1993. The Design of Economic Policy under Model Uncertainty. Computational Economics 6:219-240.

Clarida, Richard, Jordi Gali and Mark Gertler. 1997. The Science of Monetary Policy. Manuscript, New York University. . 1998. Monetary Policy Rules and Macroeconomic Stability: Evidence and Some Theory. NBER Working Paper No. 6442.

Cooper, J. P. and Stanley Fischer. 1974. Monetary and Fiscal Policy in a Fully Stochastic St. Louis Econometric Model. Journal of Money, Credit and Banking 6:1-22.

Fair, Ray C., and E. Philip Howrey. 1996. Evaluating Alternative Monetary Policy Rules. Journal of Monetary Economics 38:173-193.

Fischer, Stanley. 1977. Long-term Contracts, Rational Expectations, and the Optimal Money Supply Rule. Journal of Political Economy 85:191-206.

Frankel, Jeffrey A., and Katharine E. Rockett. 1988. International Macroeconomic Policy Coordination When Policymakers Do Not Agree on the True Model. American Economic Review 78:318-340.

Fuhrer, Jeffrey. 1997a. Inflation/Output Variance Trade-Offs and Optimal Monetary Policy. Journal of Money, Credit, and Banking 29:214-234. . 1997b. Towards a Compact, Empirically-Verified Rational Expectations Model for Monetary Policy Analysis. Carnegie-Rochester Conference Series on Public Policy, forthcoming.

and Brian Madigan. 1997. Monetary Policy when Interest Rates are Bounded at Zero. Review of Economics and Statistics 79:573-85. 
and George R. Moore. 1995. Inflation Persistence. Quarterly Journal of Economics 110:127-59.

Goodfriend, Marvin. 1991. Interest Rates and the Conduct of Monetary Policy. CarnegieRochester Conference Series on Public Policy, 34:7-30.

Goodhart, Charles. 1996. Why do the Monetary Authorities Smooth Interest Rates? London School of Economics Financial Markets Group Special Paper No. 81.

. 1998. Keynes Lecture to the British Academy: Central Bankers and Uncertainty. Manuscript, London School of Economics.

Hansen, Lars P., and Thomas J. Sargent. 1997. Recursive Linear Models of Dynamic Economies. Manuscript, University of Chicago.

Holtham, Gerald and Andrew Hughes-Hallett. 1992. International Macroeconomic Policy Coordination When Policymakers Do Not Agree on the True Model: Comment. American Economic Review 82:1043-1056.

Henderson, Dale and Warwick J. McKibbin. 1993. A Comparison of Some Basic Monetary Policy Regimes for Open Economies: Implications of Different Degrees of Instrument Adjustment and Wage Persistence. Carnegie-Rochester Conference Series on Public Policy 39:221-318.

Karakitsos, E. and B. Rustem. 1984. Optimally Derived Fixed Rules and Indicators. Journal of Economic Dynamics and Control 8:33-64.

Kendrick, David. 1982. Caution and Probing in a Macroeconomic Model. Journal of Economic Dynamics and Control 4:149-170.

Leiderman, Leonardo, and Lars E. O. Svensson, editors. 1995. Inflation Targets. London: Centre for Economic Policy Research.

Levin, Andrew. 1996. A Comparison of Alternative Monetary Policy Rules in the Federal Reserve Board's Multi-Country Model. Bank for International Settlements Conference Papers 2:340-366.

Levin, Andrew, John H. Rogers, and Ralph W. Tryon. 1997. Evaluating International Economic Policy with the Federal Reserve's Global Model. Federal Reserve Bulletin 10:797-817.

Lowe, Philip, and Luci Ellis. 1997. The Smoothing of Official Interest Rates. In Monetary Policy and Inflation Targeting: Proceedings of a Conference, ed. Philip Lowe. Sydney: Reserve Bank of Australia. 
Lucas, Robert E., Jr. 1976. Econometric Policy Evaluation: A Critique. Carnegie-Rochester Conference Series on Public Policy 1:19-46.

McCallum, Bennett. 1997. Issues in the Design of Monetary Policy Rules. NBER Working Paper 6016.

1994. Specification of policy rules and performance measures in multicountry simulations studies. Journal of International Money and Finance 13:259-275.

and Edward Nelson. 1997. An Optimising IS-LM Specification for Monetary Policy and Business Cycle Analysis. NBER Working Paper No. 5875.

Orphanides, Athanasios. 1998. Monetary Policy Rules Based on Real-Time Data. Finance and Economics Discussion Series 98-3. Washington, DC: Board of Governors of the Federal Reserve System.

and Volker Wieland. 1997. Price Stability and Monetary Policy Effectiveness when Nominal Interest Rates are Bounded at Zero. Finance and Economics Discussion Series 98-35. Washington, DC: Board of Governors of the Federal Reserve System.

David Small, Volker Wieland, and David W. Wilcox. 1997. A Quantitative Exploration of the Opportunistic Approach to Disinflation. Finance and Economics Discussion Series 97-36. Washington, DC: Board of Governors of the Federal Reserve System.

Phelps, Edmund S. and John B. Taylor. 1977. Stabilizing Powers of Monetary Policy under Rational Expectations. Journal of Political Economy 85:163-190.

Phillips, A. W. 1954. Stabilization Policies in a Closed Economy. Economic Journal 64:290-323.

Poole, William. 1970. The Optimal Choice of Instruments in a Simple Stochastic Macro Model. Quarterly Journal of Economics 84:197-216.

Rebelo, Sergio and Danyang Xie. 1997. On the Optimality of Interest Rate Smoothing. NBER Working Paper 5947.

Reifschneider, David and John C. Williams. 1998. Three Lessons for Monetary Policy in a Low Inflation Era. Manuscript, Board of Governors of the Federal Reserve System. 
Rotemberg, Julio and Michael Woodford. 1997. An Optimization-Based Econometric Framework for the Evaluation of Monetary Policy. NBER Macroeconomics Annual. Cambridge, MA: MIT Press.

Sumner, Steven and John C. Williams. 1998. Evaluating Solution Methods for Linear Rational Expectations Models. Manuscript, Board of Governors of the Federal Reserve System.

Svensson, Lars E.O. 1997a. Open-Economy Inflation Targeting", Manuscript, Stockholm University. . 1997b. Inflation-Forecast-Targeting: Implementing and Monitoring Inflation Targets. European Economic Review 41:1111-46.

Taylor, John B. 1979. Estimation and Control of a Macroeconomic Model with Rational Expectations. Econometrica 47:1267-86.

. 1980. Aggregate Dynamics and Staggered Contracts. Journal of Political Economy 88:1-23.

. 1993a. Discretion versus Policy Rules in Practice. Carnegie-Rochester Conference Series on Public Policy 39:195-214.

. 1993b. Macroeconomic Policy in the World Economy: From Econometric Design to Practical Operation. New York: W.W.Norton.

. 1995. Monetary Policy Implications of Greater Fiscal Discipline. In Budget Deficits and Debt:Issues and Options. Federal Reserve Bank of Kansas City.

and John C. Williams. 1993. Forecasting with Rational Expectations Models. Manuscript, Board of Governors of the Federal Reserve System.

Tetlow, Robert, and Peter von zur Muehlen. 1996. Monetary Policy Rules (I): How Good is Simple? Manuscript, Board of Governors of the Federal Reserve System.

Tinsley, Peter. 1993. Fitting Both Data and Theories: Polynomial Adjustment Costs and ErrorCorrection Rules. Finance and Economics Discussion Paper 93-21. Washington, DC: Board of Governors of the Federal Reserve System.

Wieland, Volker. 1996a. Monetary Policy Targets and the Stabilization Objective: A Source of Tension in the EMS. Journal of International Money and Finance 15:95-116.

. 1996b. Monetary Policy, Parameter Uncertainty and Optimal Learning. Manuscript, Board of Governors of the Federal Reserve System. 
$-38-$

1998. Monetary Policy and Uncertainty about the Natural Unemployment Rate. Finance and Economics Discussion Series 98-22. Washington, DC: Board of Governors of the Federal Reserve System.

Williams, John C. 1997. Simple Rules for Monetary Policy. Manuscript, Board of Governors of the Federal Reserve System. 
Table 1

Comparison of Model Specifications

\begin{tabular}{|c|c|c|c|c|}
\hline & FM & MSR & FRB & TMCM \\
\hline IS Components & 1 & 5 & 17 & 10 \\
\hline Price Variables & 2 & 2 & 7 & 5 \\
\hline Labor Variables & 0 & 0 & 4 & 0 \\
\hline Asset Prices & 1 & 2 & 7 & 2 \\
\hline Foreign Variables & 0 & 0 & $3^{2}$ & 95 \\
\hline $\begin{array}{c}\text { Wage and Price } \\
\text { Dynamics }\end{array}$ & $\begin{array}{l}\text { Staggered } \\
\text { real wage } \\
\text { contracts }\end{array}$ & $\begin{array}{l}\text { Staggered } \\
\text { real wage } \\
\text { contracts }\end{array}$ & $\begin{array}{l}\text { Generalized } \\
\text { adjustment } \\
\text { costs }\end{array}$ & $\begin{array}{c}\text { Staggered } \\
\text { nominal wage } \\
\text { contracts }\end{array}$ \\
\hline Maturity of Bond & 30 years & 2 years & 5 years $^{3}$ & 2 years \\
\hline $\begin{array}{l}\text { Permanent Income } \\
\text { Discount Rate }\end{array}$ & N/A & $\begin{array}{l}10 \% \\
\text { per quarter }\end{array}$ & $\begin{array}{l}7 \% \\
\text { per quarter }\end{array}$ & $\begin{array}{c}10 \% \\
\text { per quarter }\end{array}$ \\
\hline Estimation Period & $1982-94^{1}$ & $1980-96$ & 1966-95 & $1971-86$ \\
\hline
\end{tabular}

\section{Notes:}

1. The parameters of the FM model were estimated using the sample period 1966Q1 to 1994Q1. However, in constructing the innovation covariance matrix, we only use residuals for the period 1982Q4 to 1994Q1.

2. The full FRB model contains over 400 foreign variables; in the version of the FRB model used in this paper, these have been replaced by 3 equations for foreign output, foreign prices, and the price of imported oil.

3. The FRB model includes bonds with maturities of 5, 10, and 30 years, as well as equity prices. The five year bond is used in computing the cost of capital for business equipment and consumer purchases of durables. 
Table 2

Comparison of Output Dynamics

\begin{tabular}{cccccc} 
& \multicolumn{2}{c}{ Models } & & U.S. Data \\
\cline { 2 - 5 } Coefficient & FM & MSR & TMCM & FRB & 1966:1-1995:4 \\
\hline$\delta$ & 0.04 & 0.17 & 0.31 & 0.05 & 0.10 \\
0 & 0.49 & 0.45 & -0.04 & 0.26 & $0.03)$ \\
& & & & & $(0.08)$ \\
$\phi$ & 0.03 & 0.05 & 0.06 & 0.04 & 0.08 \\
& & & & & $(0.03)$ \\
\hline
\end{tabular}

Note: This table considers the regression equation $\Delta y_{\mathrm{t}}=-\delta y_{\mathrm{t}-1}+\theta \Delta y_{\mathrm{t}-1}-\varphi\left(\mathbf{r}_{\mathrm{t}-1}-\mathrm{E}_{\mathrm{t}-1} \pi_{\mathrm{t}}\right)+\varepsilon_{\mathrm{t}}$, where $\boldsymbol{y}_{\mathrm{t}}$ is the output gap and $\mathbf{r}_{\mathrm{t}}-\mathrm{E}_{\mathrm{t}} \boldsymbol{\pi}_{\mathrm{t}+1}$ is the ex ante real federal funds rate. The first four columns report asymptotic values of $\delta, \theta$, and $\phi$ for each of the four models, while the final column reports the coefficient estimates and OLS standard errors of this regression equation using U.S. data for the sample period 1966Q1-1995Q4. For the data regression, expected inflation is proxied by the lagged inflation rate.

Table 3

Parameter Values of Alternative Simple Rules

\begin{tabular}{cccc} 
& \multicolumn{3}{c}{ Parameters } \\
\cline { 2 - 4 } Policy & & $\boldsymbol{\beta}$ & $\boldsymbol{\rho}$ \\
\hline $\mathrm{Aule}$ & $\boldsymbol{\alpha}$ & 0.6 & 1 \\
$\mathrm{~B}$ & 1.3 & 1.0 & 1 \\
$\mathrm{C}$ & 0.8 & 0.8 & 1 \\
$\mathrm{D}$ & 3.0 & 1.0 & 1 \\
$\mathrm{~T}$ & 1.2 & 0.5 & 0 \\
$\mathrm{~T} 2$ & 0.5 & 1.0 & 0 \\
$\mathrm{~V}$ & 0.5 & 0.06 & 1.3 \\
$\mathrm{~W}$ & 1.5 & 0.08 & 1.3 \\
\hline
\end{tabular}


Table 4

$\underline{\text { Rule Comparison Table }}$

Standard Deviations

\begin{tabular}{|c|c|c|c|c|c|}
\hline \multirow[b]{2}{*}{ Model } & \multirow[b]{2}{*}{ Rule } & \\
\hline & & $\operatorname{SD}(y)$ & $\operatorname{SD}(\pi)$ & $\operatorname{SD}(\mathbf{r})$ & $\mathbf{S D}(\triangle \mathbf{r})$ \\
\hline \multirow[t]{8}{*}{ FM } & $\mathbf{A}$ & 3.78 & 1.85 & 8.89 & 1.97 \\
\hline & B & 2.37 & 2.45 & 7.71 & 1.83 \\
\hline & $\mathbf{C}$ & 5.15 & 1.60 & 15.39 & 3.92 \\
\hline & D & 2.85 & 2.17 & 8.61 & 2.07 \\
\hline & $\mathbf{T}$ & 2.68 & 2.63 & 3.57 & 0.75 \\
\hline & $\mathbf{T} 2$ & 2.32 & 2.84 & 3.83 & 0.90 \\
\hline & $\mathbf{V}$ & 21.2 & 7.13 & 27.2 & 4.38 \\
\hline & $\mathbf{W}$ & 20.5 & 6.57 & 27.9 & 4.59 \\
\hline \multirow[t]{8}{*}{ MSR } & $\mathbf{A}$ & 0.84 & 0.4 & 1.17 & 0.34 \\
\hline & B & 0.58 & 0.53 & 1.33 & 0.48 \\
\hline & C & 1.07 & 0.29 & 1.40 & 0.43 \\
\hline & D & 0.64 & 0.44 & 1.35 & 0.48 \\
\hline & $\mathbf{T}$ & 0.99 & 0.70 & 1.01 & 0.30 \\
\hline & $\mathbf{T} 2$ & 0.87 & 0.73 & 1.19 & 0.50 \\
\hline & V & 1.95 & 0.41 & 1.31 & 0.19 \\
\hline & W & 1.88 & 0.38 & 1.3 & 0.19 \\
\hline \multirow[t]{8}{*}{ FRB } & $\mathbf{A}$ & 2.12 & 1.46 & 4.34 & 1.22 \\
\hline & B & 1.41 & 1.65 & 4.5 & 1.22 \\
\hline & C & 2.77 & 1.37 & 7.11 & 2.34 \\
\hline & D & 1.62 & 1.56 & 4.84 & 1.39 \\
\hline & $\mathbf{T}$ & 2.92 & 1.86 & 2.51 & 0.9 \\
\hline & $\mathbf{T} 2$ & 2.21 & 2.02 & 3.16 & 1.2 \\
\hline & $\mathbf{V}$ & 6.32 & 1.55 & 4.67 & 1.11 \\
\hline & $\mathbf{W}$ & 6.06 & 1.53 & 4.88 & 1.19 \\
\hline
\end{tabular}


Table 4 (contd.)

Rule Comparison Table

\begin{tabular}{cccccc} 
TMCM & A & 2.33 & 1.73 & 4.78 & 1.71 \\
& B & 1.95 & 1.79 & 5.03 & 2.01 \\
& C & 2.70 & 1.68 & 6.72 & 2.80 \\
& D & 1.95 & 1.79 & 5.03 & 2.01 \\
& T & 2.89 & 2.58 & 4.00 & 1.58 \\
& T2 & 2.55 & 2.36 & 4.35 & 2.41 \\
& V & 4.31 & 2.06 & 4.24 & 1.24 \\
& W & 4.26 & 2.02 & 4.47 & 1.33 \\
\hline U.S. Data & & 2.4 & 2.1 & 3.7 & 1.3 \\
\hline
\end{tabular}

Note: The U.S. data uses a measure of potential output provided by the Congressional Budget Office. Caution should be used in comparing the sample moments with those of each model, because the sample period involves an exceptionally high initial inflation rate, whereas the model-based moments are unconditional deviations from steady state.

Table 5

Volatility of Funds Rate Levels and Changes

\begin{tabular}{|c|c|c|c|c|c|c|}
\hline \multirow[b]{2}{*}{ Model } & \multicolumn{2}{|c|}{ E Frontier } & \multicolumn{2}{|c|}{$\frac{\text { Alternative Frontier with }}{\text { Doubled Volatility }}$} & \multicolumn{2}{|c|}{$\frac{\text { Alternative Frontier }}{\text { with Tripled Volatility }}$} \\
\hline & $\operatorname{SD}(\Delta \mathbf{r})$ & $\operatorname{SD}(\mathbf{r})$ & $\operatorname{SD}(\Delta \mathbf{r})$ & $\operatorname{SD}(\mathbf{r})$ & $\operatorname{SD}(\Delta r)$ & $\operatorname{SD}(\mathbf{r})$ \\
\hline FM & 1 & 5 & 2 & 7 & 3 & 9 \\
\hline MSR & 0.6 & 1.5 & 1.2 & 2.3 & 1.7 & 2.9 \\
\hline FRB & 1.2 & 4.5 & 2.4 & 6 & 3.7 & 9 \\
\hline ТМСМ & 2.6 & 6 & 5.1 & 9 & 7.7 & 11 \\
\hline
\end{tabular}


Table 6

Performance of Simple Rules Under Model Uncertainty

\begin{tabular}{|c|c|c|c|c|c|c|c|}
\hline \multirow[b]{2}{*}{ Model } & \multirow[b]{2}{*}{ Rule } & \multicolumn{3}{|c|}{ Standard Deviations } & \multicolumn{3}{|c|}{ Objective Function } \\
\hline & & $\mathbf{y}$ & $\pi$ & $\Delta \mathbf{r}$ & Value & Loss & Implicit $\lambda$ \\
\hline \multirow[t]{2}{*}{ FM } & $\mathbf{A}$ & 3.78 & 1.85 & 1.97 & 6.15 & 0.86 & 0.1 \\
\hline & B & 2.37 & 2.45 & 1.83 & 5.72 & 1.28 & 0.4 \\
\hline \multirow[t]{2}{*}{ MSR } & $\mathbf{A}$ & 0.84 & 0.4 & 0.33 & 0.3 & 0.01 & 0.15 \\
\hline & B & 0.58 & 0.53 & 0.48 & 0.33 & 0 & 0.45 \\
\hline \multirow[t]{2}{*}{ TMCM } & $\mathbf{A}$ & 2.33 & 1.73 & 1.71 & 3.61 & 0.17 & 0.1 \\
\hline & B & 1.94 & 1.79 & 2 & 3.64 & 0.03 & 0.4 \\
\hline
\end{tabular}

Table 7

Comparison of Foreign Monetary Policy Regimes in TMCM

\begin{tabular}{|c|c|c|c|c|c|c|}
\hline & \multicolumn{2}{|c|}{$\lambda=0.1$} & \multicolumn{2}{|c|}{$\lambda=0.25$} & \multicolumn{2}{|c|}{$\lambda=0.5$} \\
\hline & Fixed $\mu$ & EMU & Fixed $\mu$ & EMU & Fixed $\mu$ & EMU \\
\hline $\operatorname{SD}\left(y_{t}\right)$ & 2.12 & 2.13 & 1.83 & 1.83 & 1.75 & 1.75 \\
\hline $\operatorname{SD}\left(\pi_{\mathrm{t}}\right)$ & 1.73 & 1.73 & 1.8 & 1.8 & 1.84 & 1.84 \\
\hline $\boldsymbol{\alpha}$ & 1.17 & 1.16 & 1.4 & 1.4 & 1.46 & 1.46 \\
\hline$\beta$ & 1.92 & 1.92 & 0.96 & 0.96 & 0.48 & 0.48 \\
\hline
\end{tabular}

Note: This table provides information on the U.S. inflation-output volatility frontier for interest rate rules of the form $\Delta \mathbf{r}_{\mathrm{t}}=\alpha \boldsymbol{y}_{\mathrm{t}}+\beta\left(\pi_{\mathrm{t}}-\pi^{*}\right)$, where $\mathbf{r}_{\mathbf{t}}$ is the federal funds rate, $\boldsymbol{y}_{\mathrm{t}}$ is the U.S. output gap, and $\pi_{\mathrm{t}}-\pi^{*}$ indicates the deviation of U.S. inflation from the target rate. For $0<\lambda<1$, the policy frontier minimizes the objective function $\lambda \operatorname{SD}\left(y_{\mathrm{t}}\right)+(1-\lambda) \operatorname{SD}\left(\pi_{\mathrm{t}}-\pi^{*}\right)$ subject to the constraint that $\operatorname{SD}\left(\Delta \mathbf{r}_{\mathrm{t}}\right) \leq 2.57$, where $\mathrm{SD}(\boldsymbol{z})$ indicates the unconditional standard deviation of $z$. Fixed $\mu$ and EMU are the two alternative foreign monetary policy regimes described in the text above. 
Figure 1: Persistence Implications of Four Models Inflation

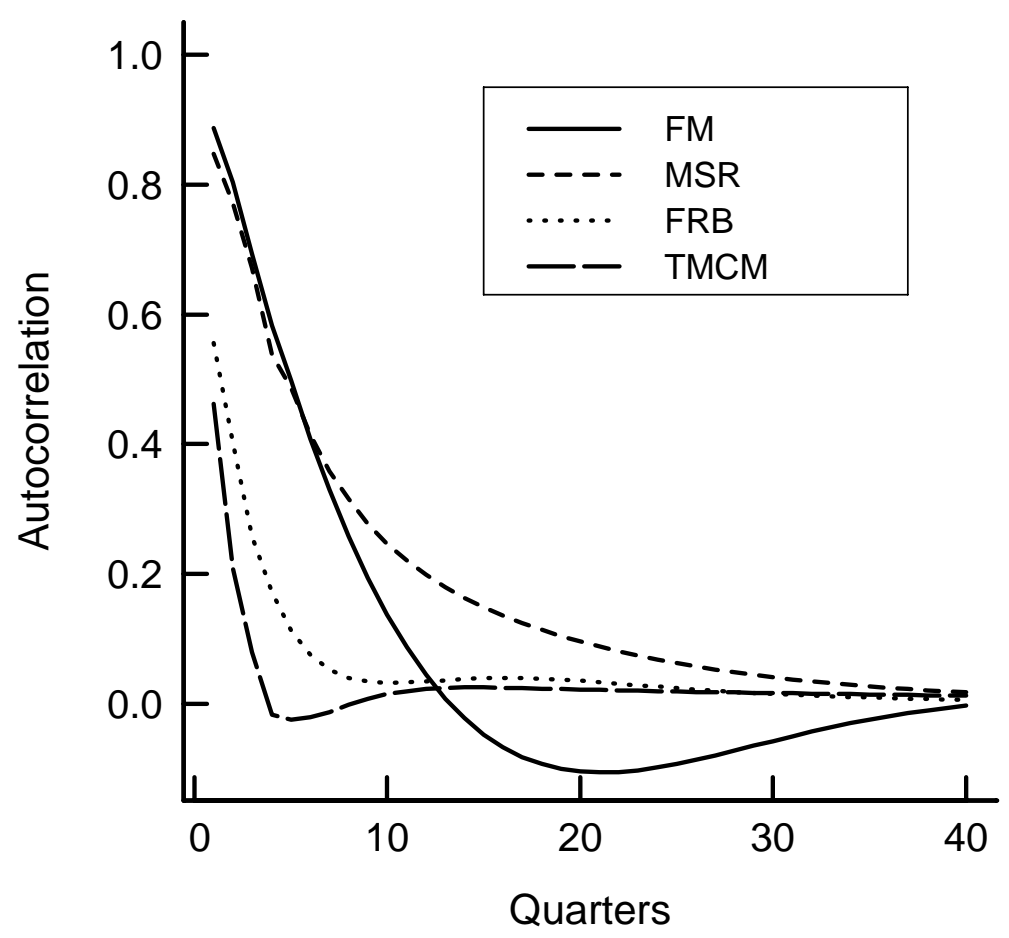

Output Gap

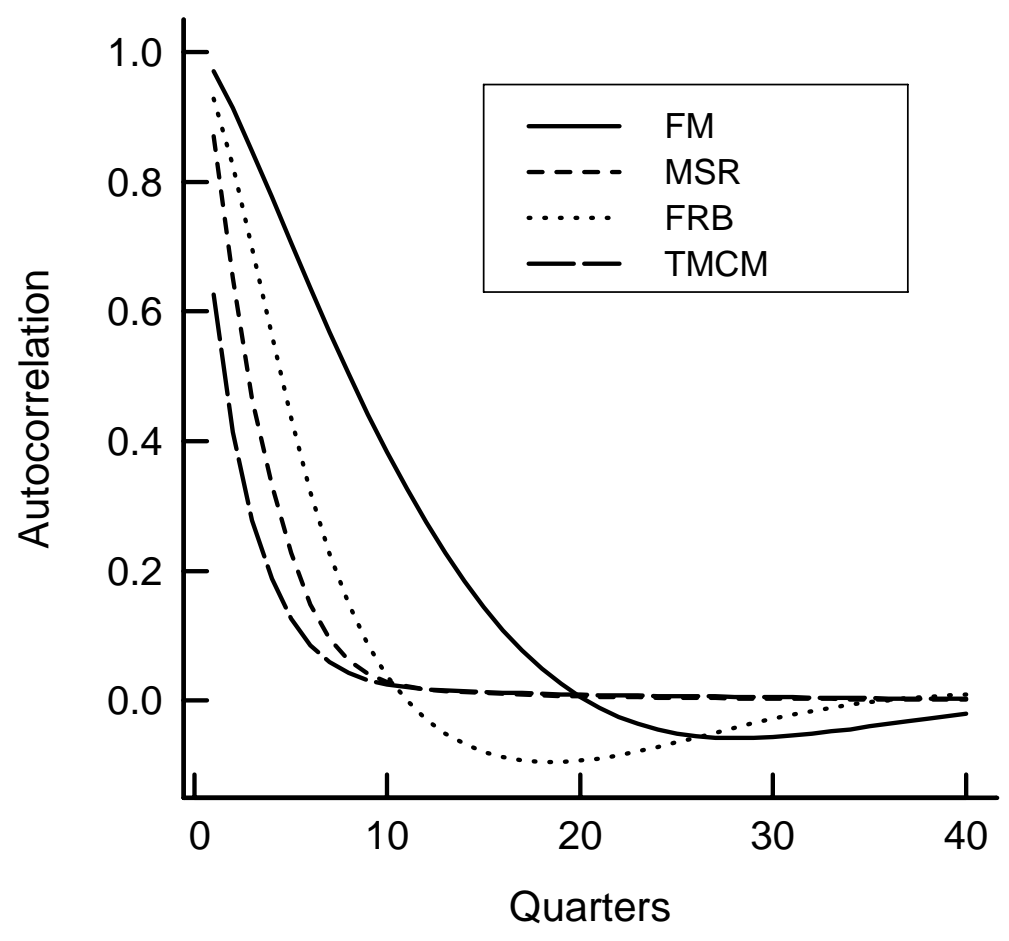


Figure 2: Policy Frontiers for 3-Parameter Rules

FM

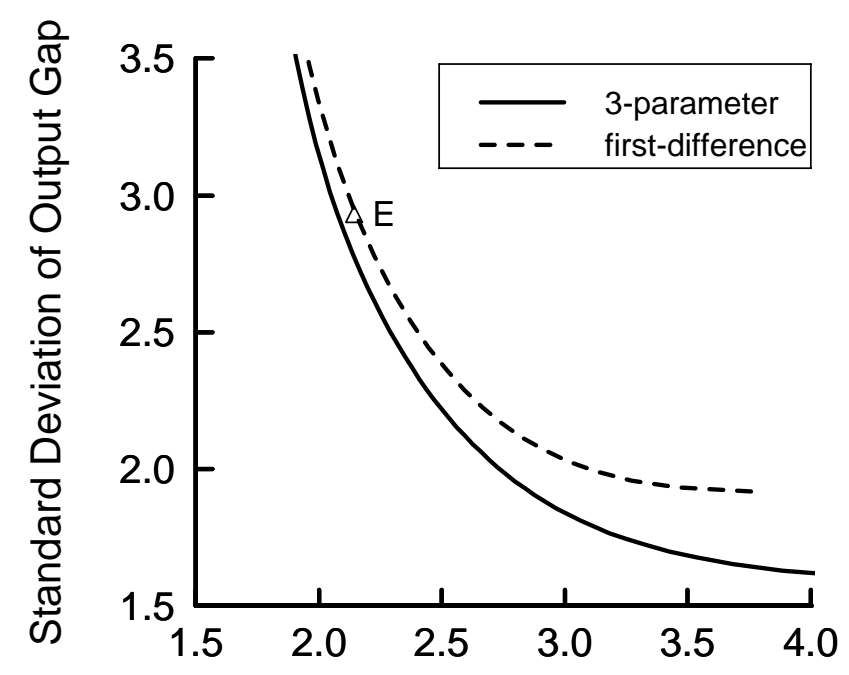

Standard Deviation of Inflation

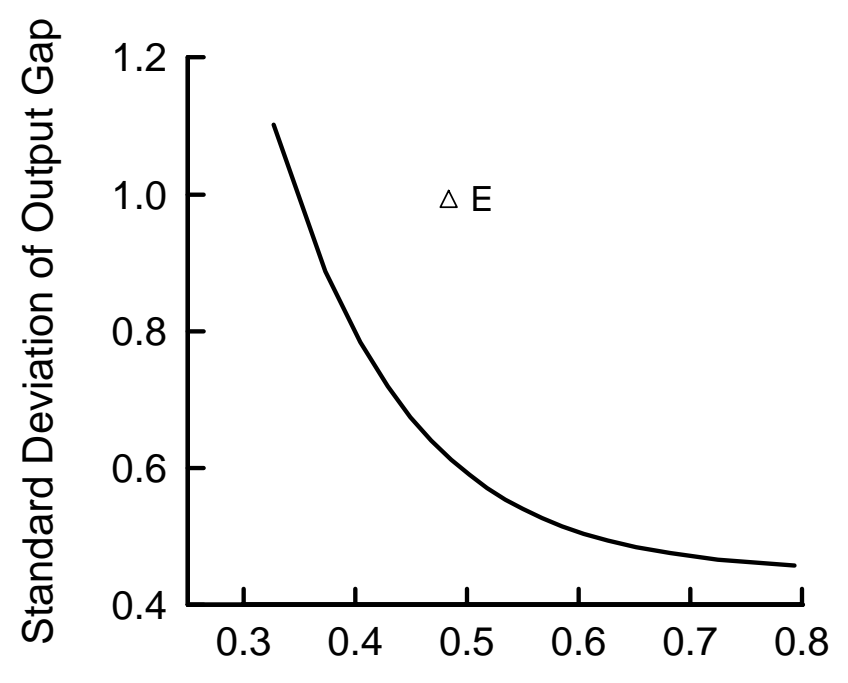

Standard Deviation of Inflation

FRB

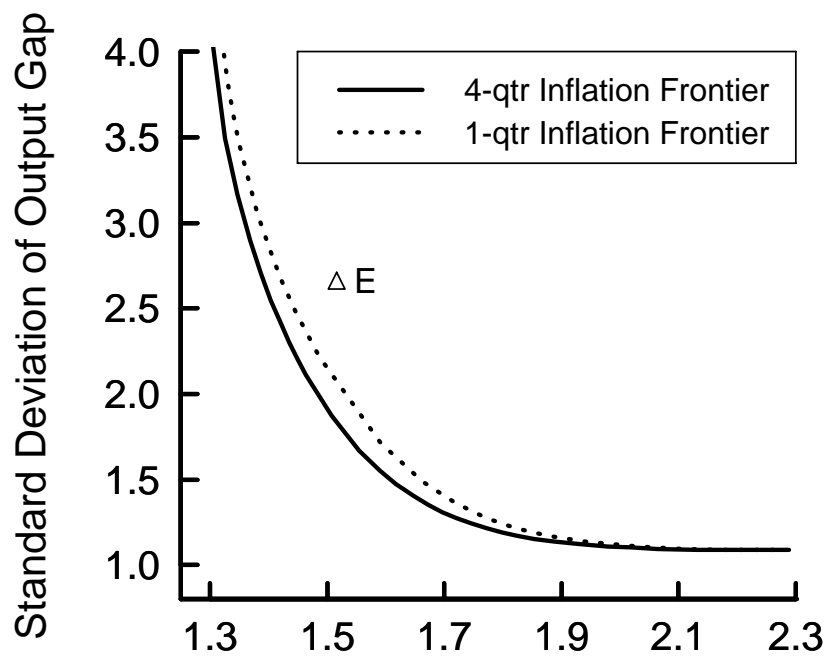

Standard Deviation of Inflation

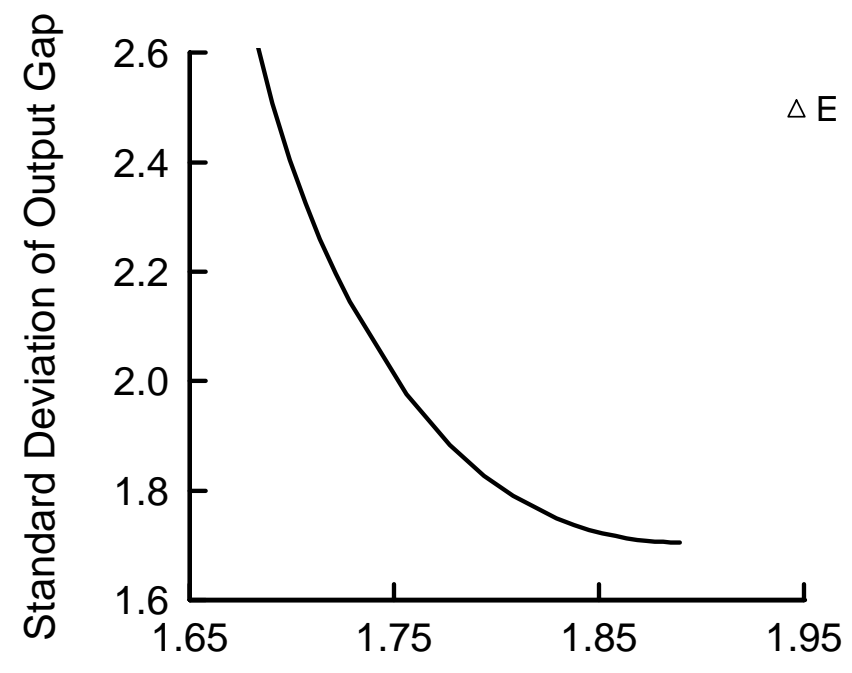

Standard Deviation of Inflation 
Figure 3: Coefficients of Optimal 3-Parameter Rules

FM

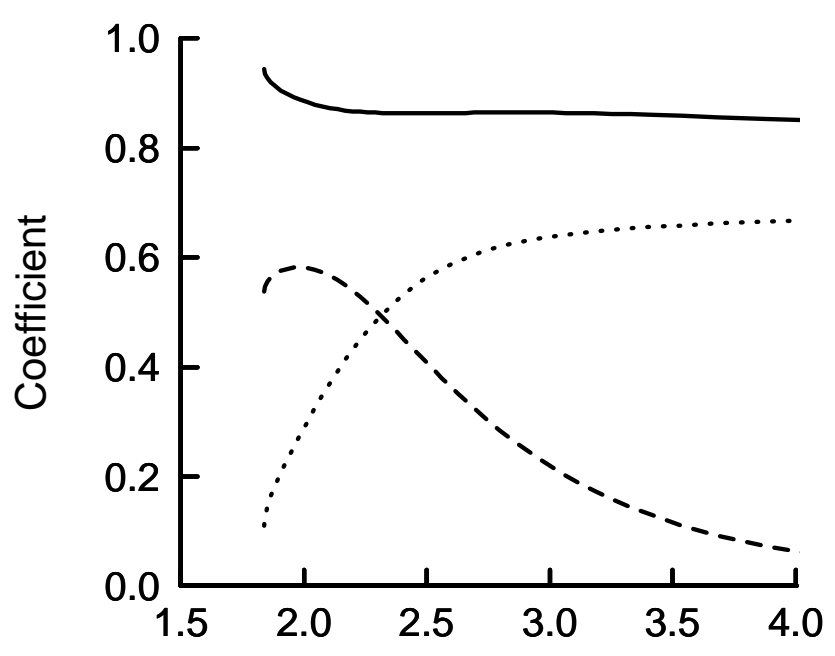

Standard Deviation of Inflation
FRB

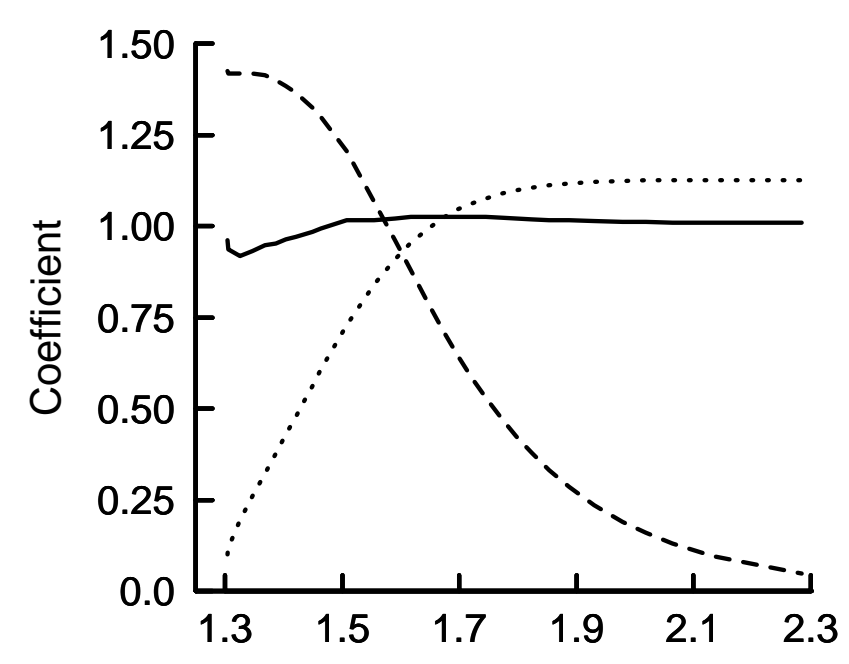

Standard Deviation of Inflation
Standard Deviation of Inflation

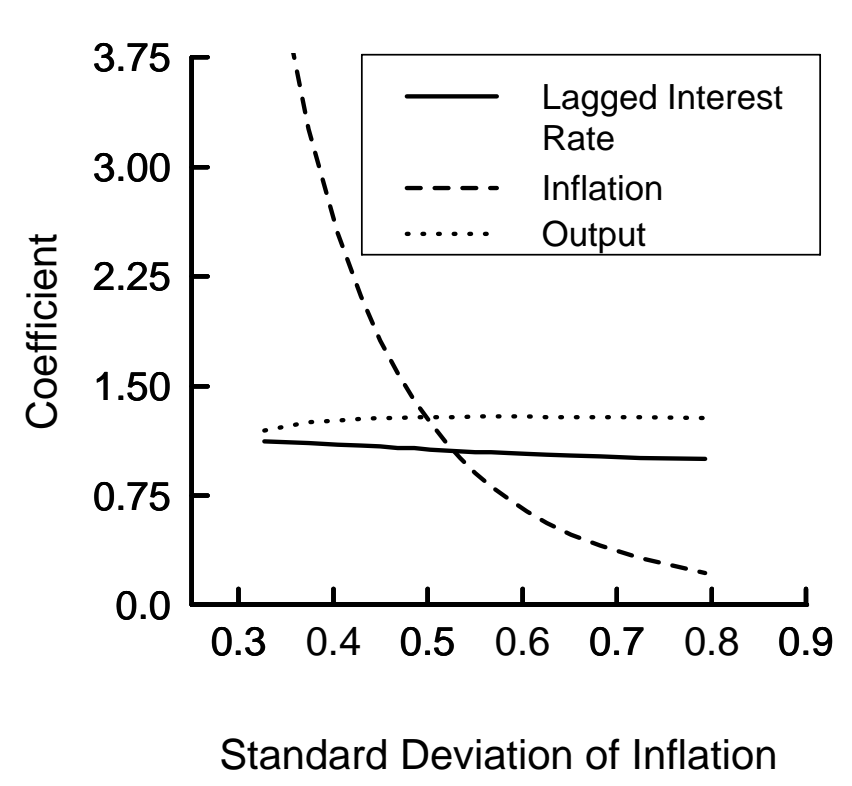

MSR

TMCM

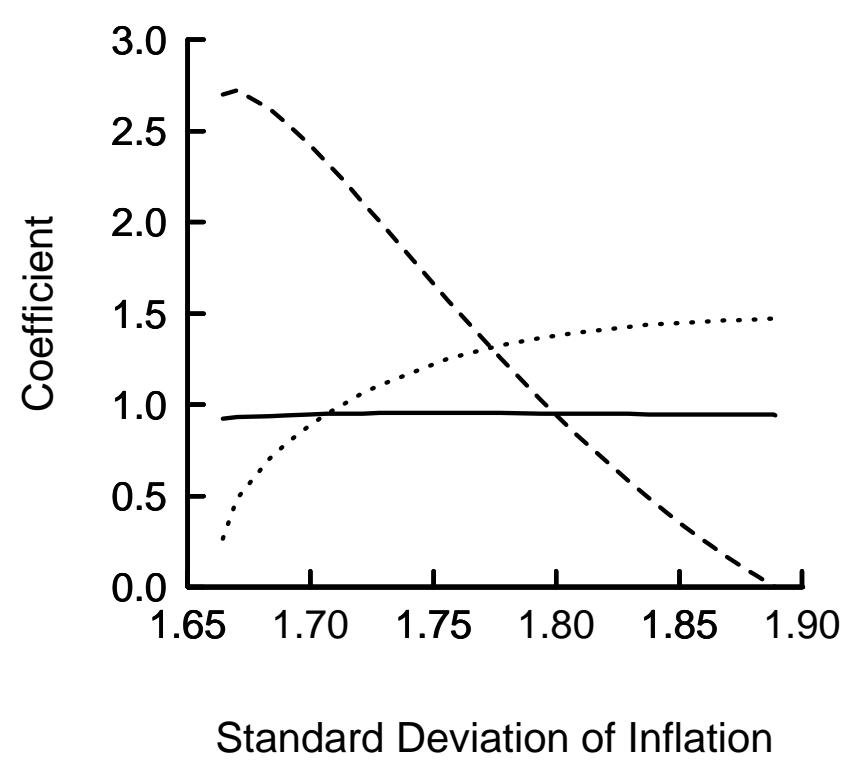


Figure 4: Policy Frontiers for Complicated Rules

FM

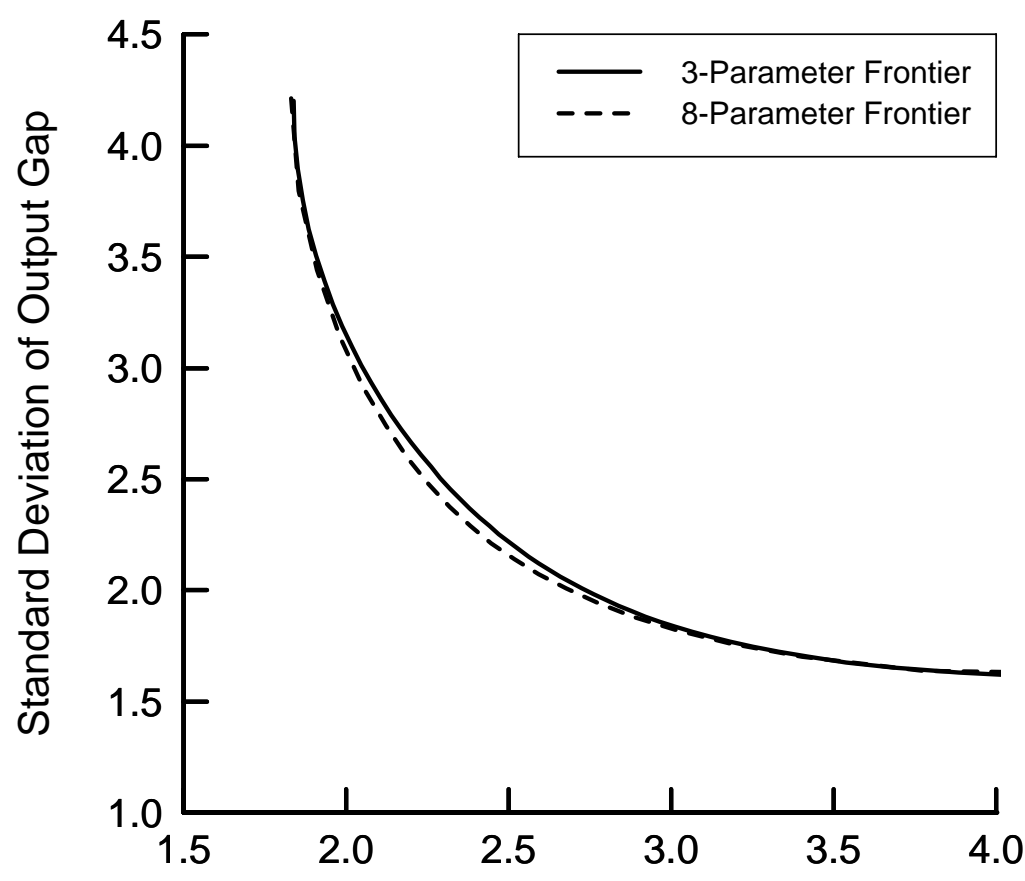

Standard Deviation of Inflation

MSR

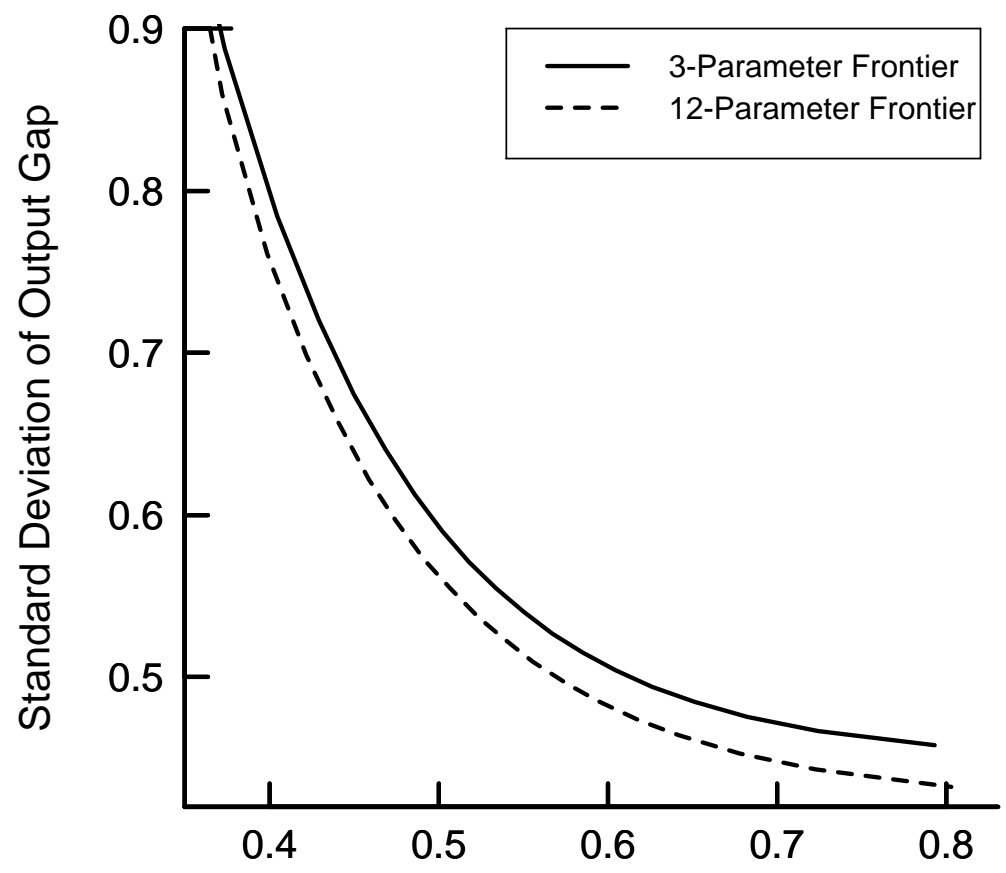

Standard Deviation of Inflation 
Figure 5: Implications of Using Lagged Information

FM

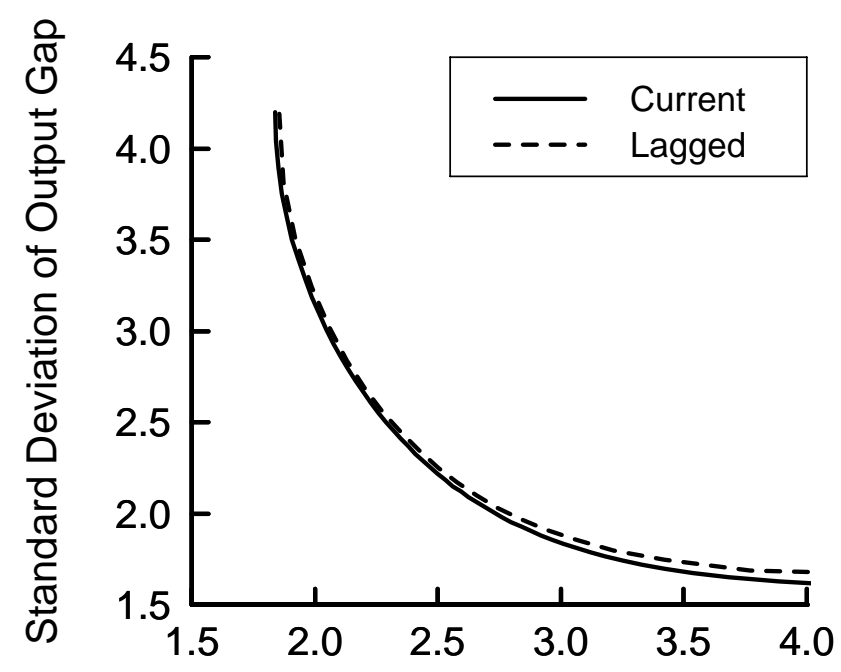

Standard Deviation of Inflation

FRB

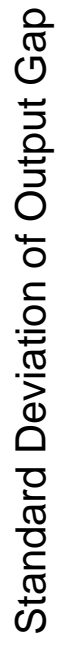

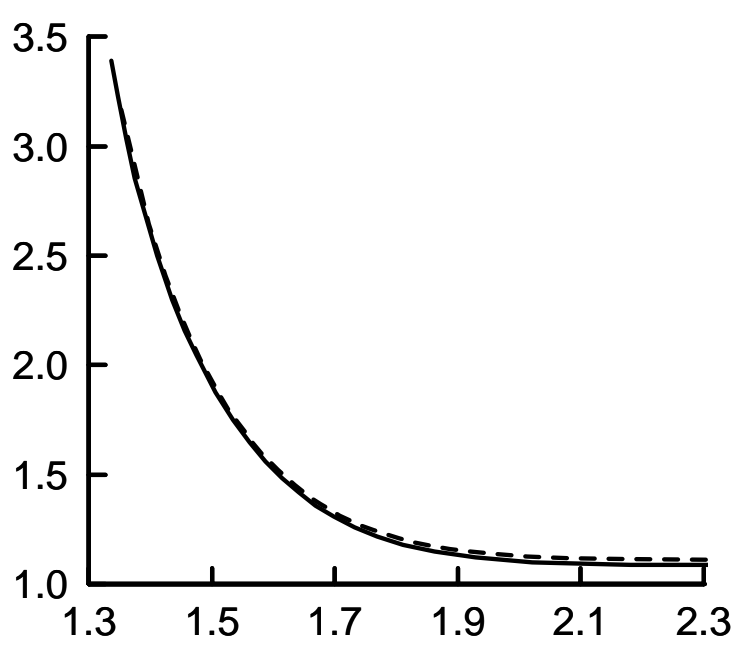

Standard Deviation of Inflation
MSR

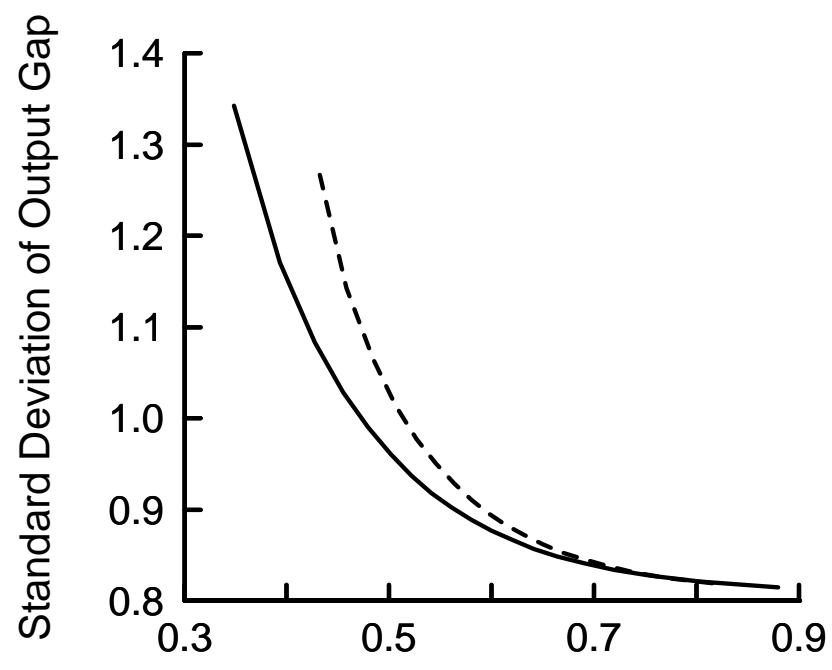

Standard Deviation of Inflation

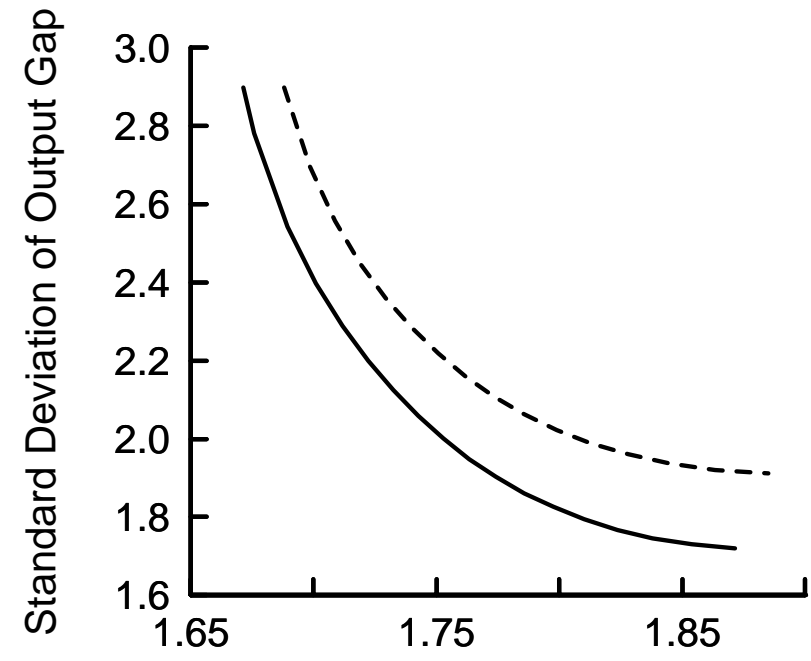

Standard Deviation of Inflation 
Figure 6: Comparison with Level Rules

FM

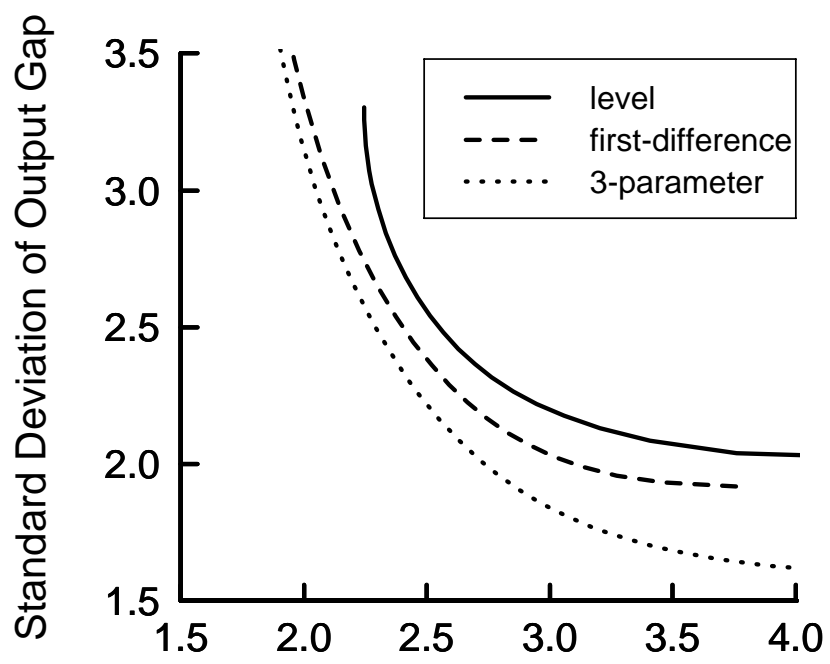

Standard Deviation of Inflation

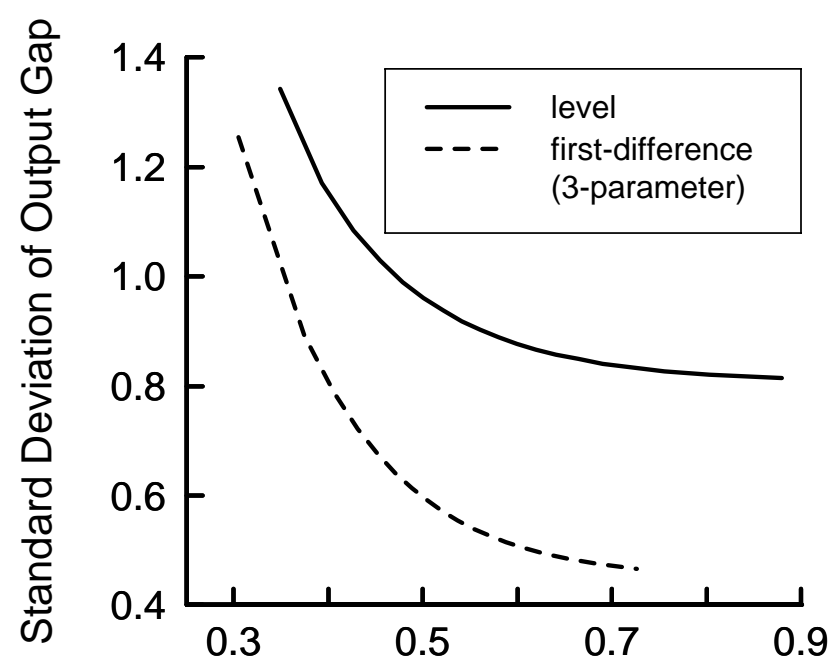

Standard Deviation of Inflation
FRB

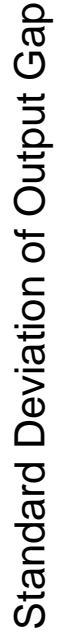

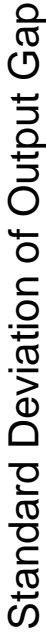

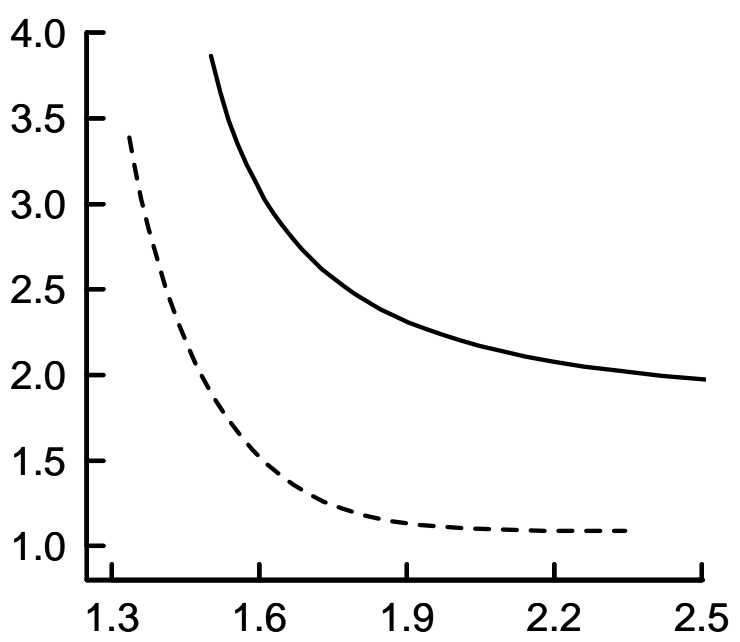

Standard Deviation of Inflation
MSR first-difference

TMCM

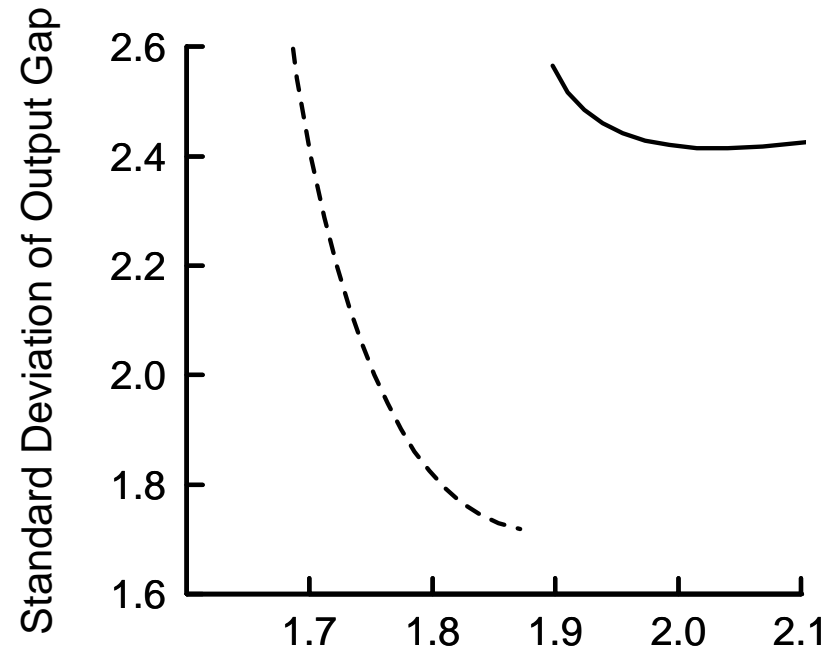

Standard Deviation of Inflation 
Figure 7: Alternative Constraints on Funds Rate Volatility

FM

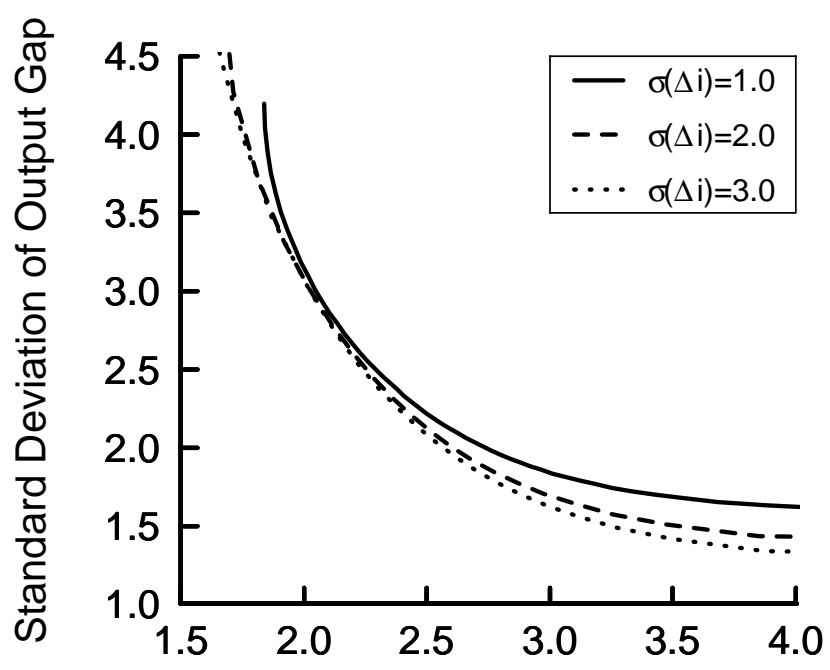

Standard Deviation of Inflation
FRB

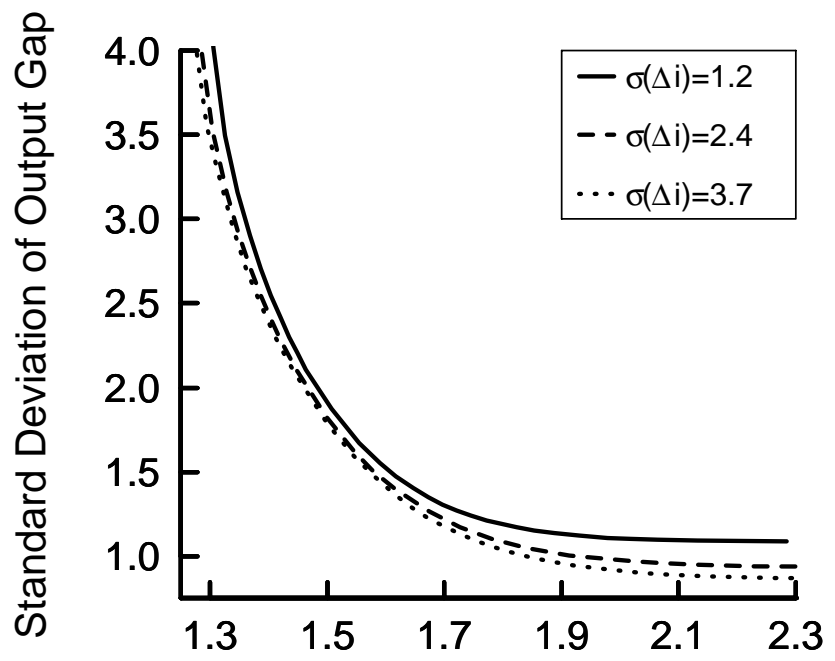

Standard Deviation of Inflation
Standard Deviation of Inflation

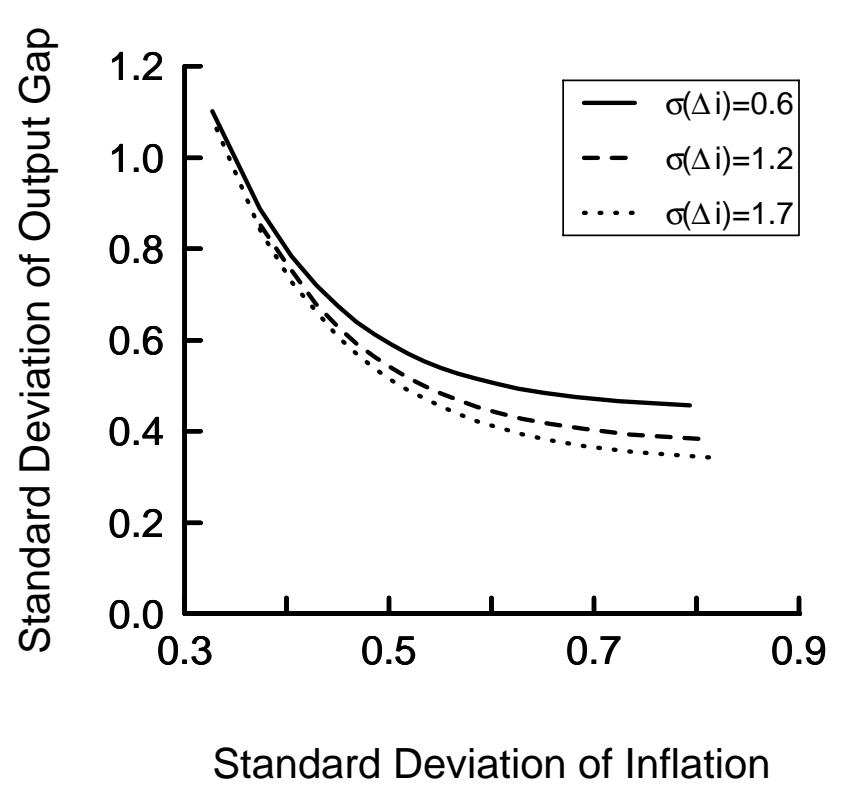

MSR

TMCM

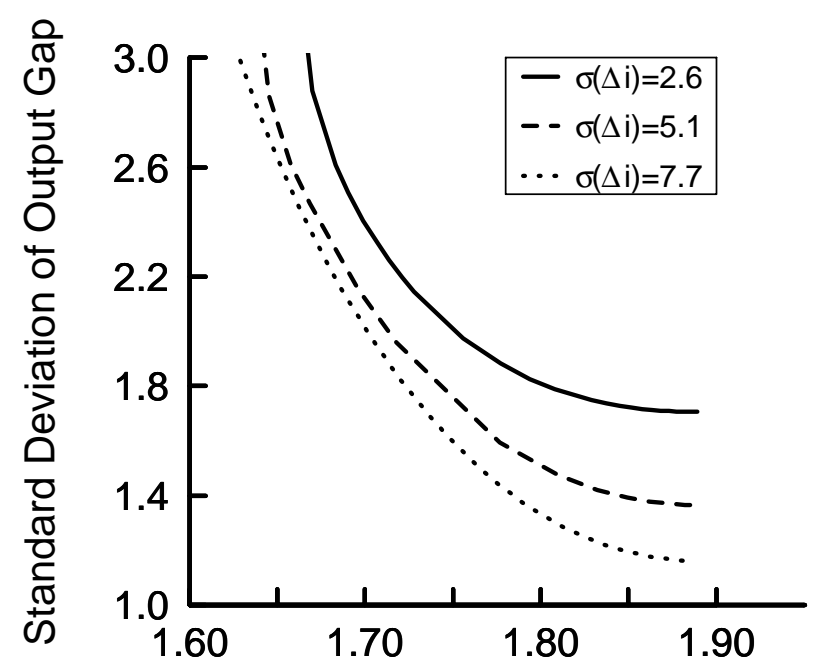

Standard Deviation of Inflation 
Figure 8: Aggregate Demand Shocks under Alternative Rules

\section{FM}
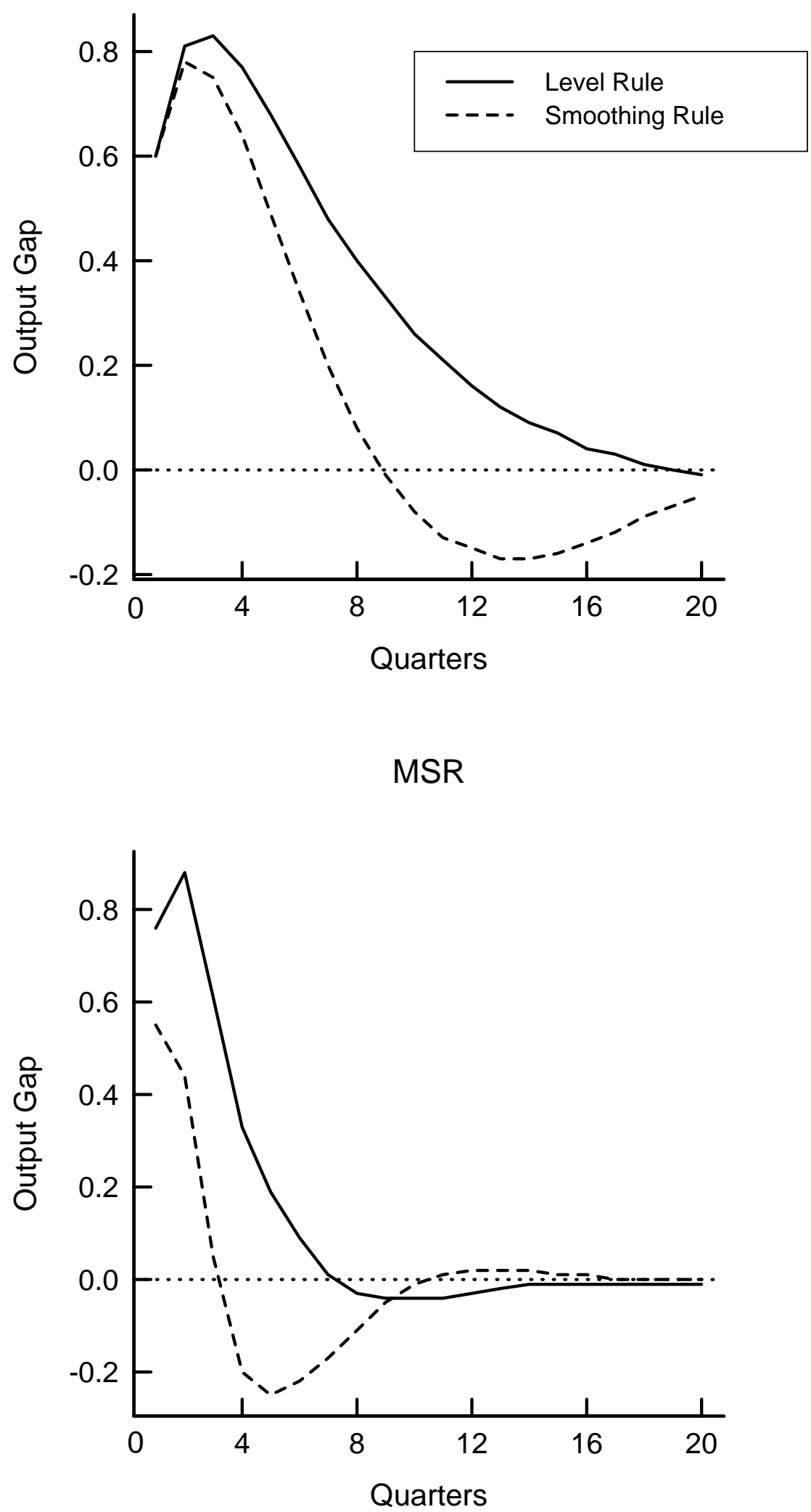
Figure 9: Performance of Simple Rules under Model Uncertainty

FM

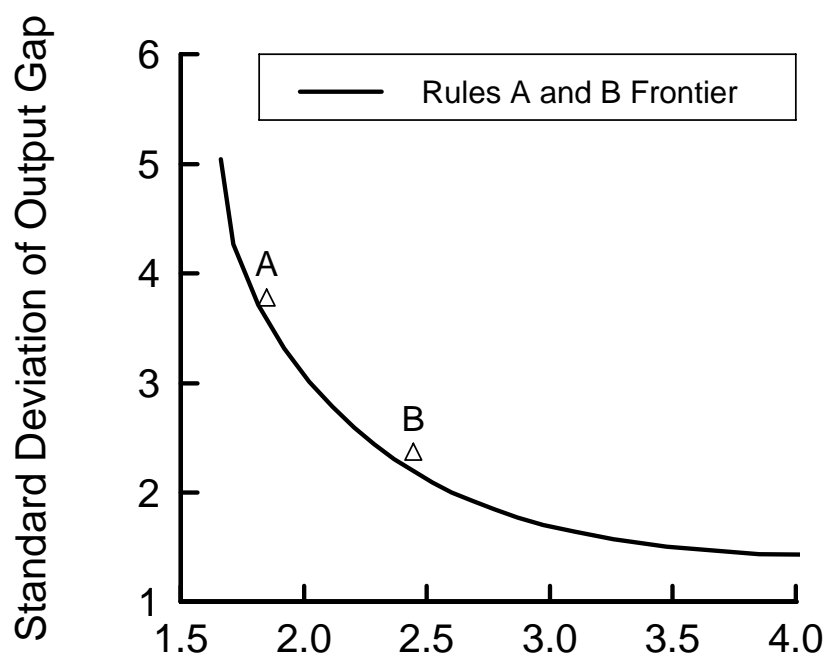

Standard Deviation of Inflation

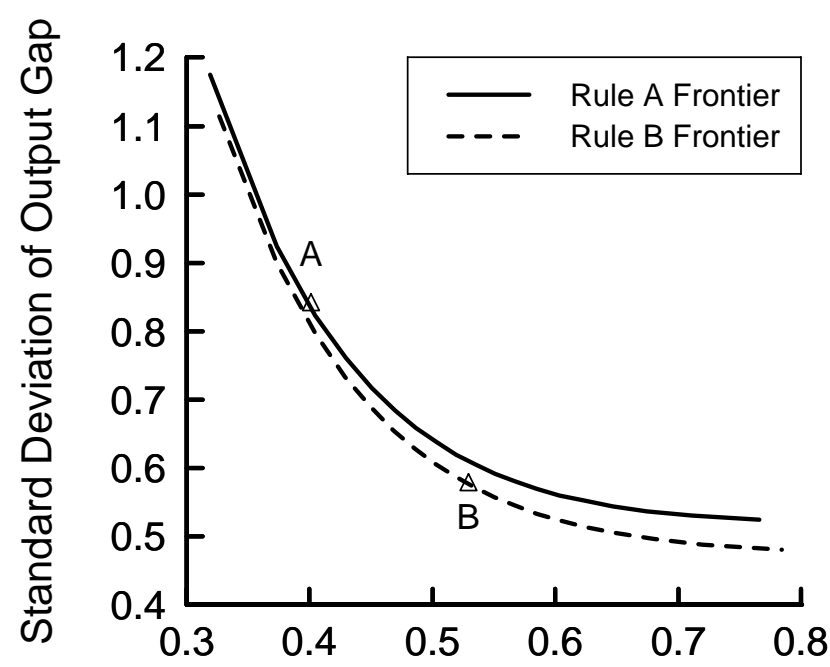

Standard Deviation of Inflation

FRB

TMCM

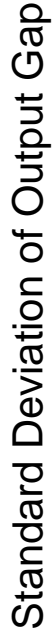
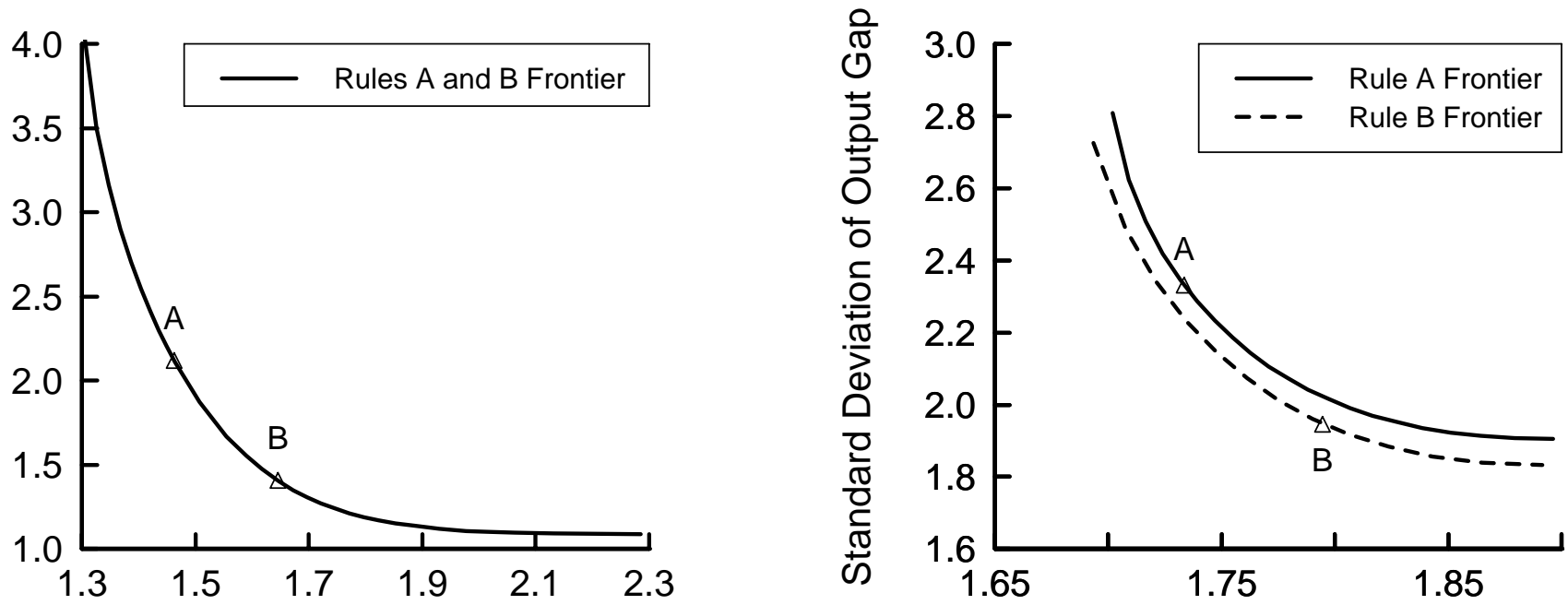

Standard Deviation of Inflation 
Figure 10: Two Complicated Rules from MSR

FM

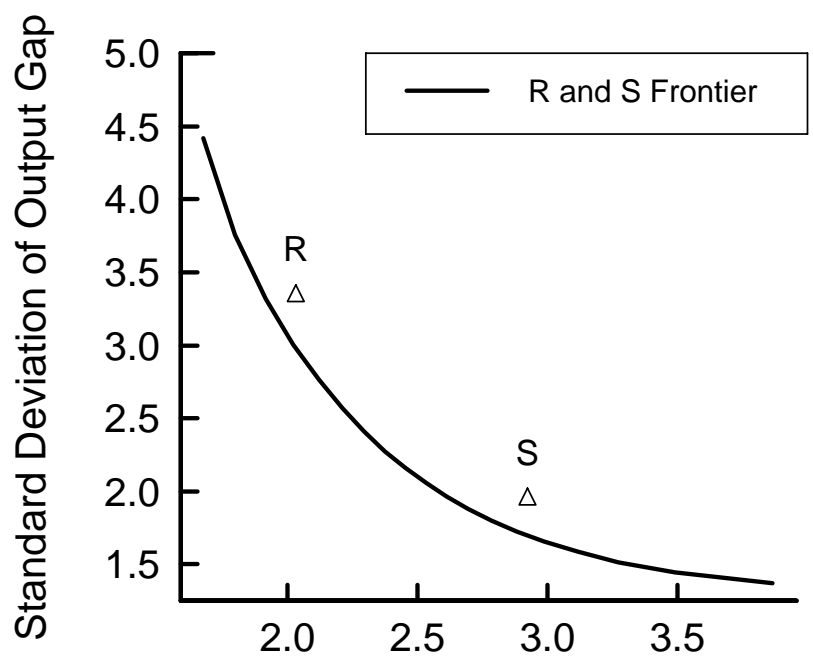

Standard Deviation of Inflation

FRB

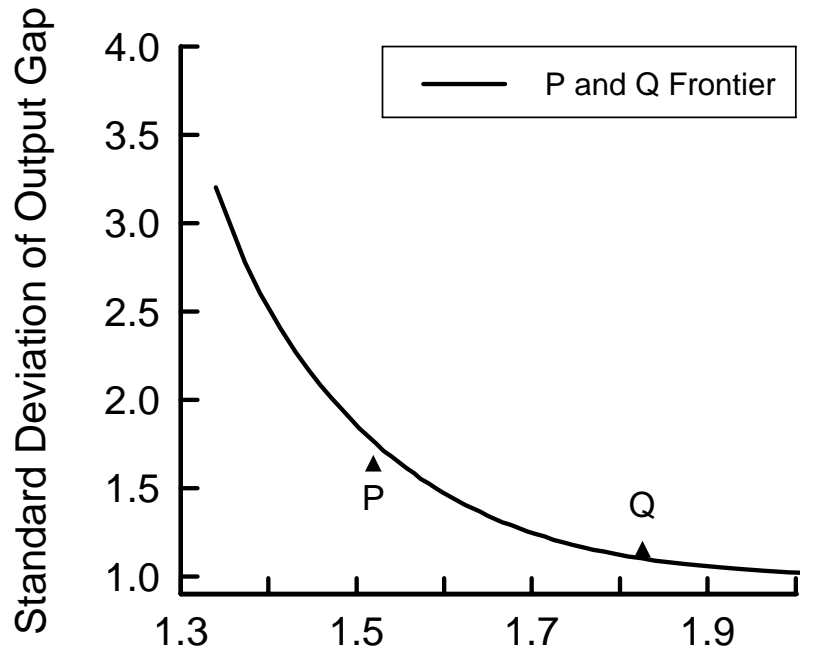

Standard Deviation of Inflation
MSR

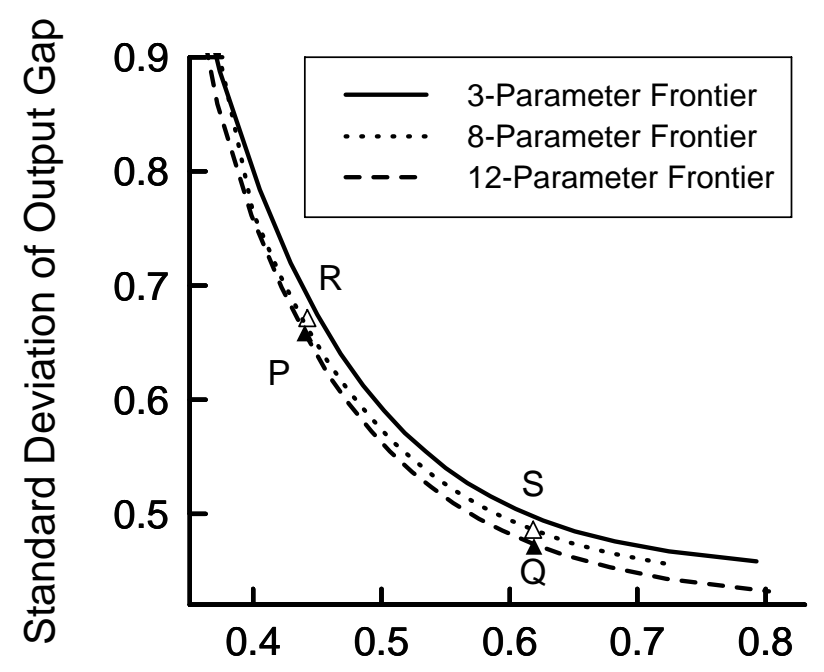

Standard Deviation of Inflation

TMCM

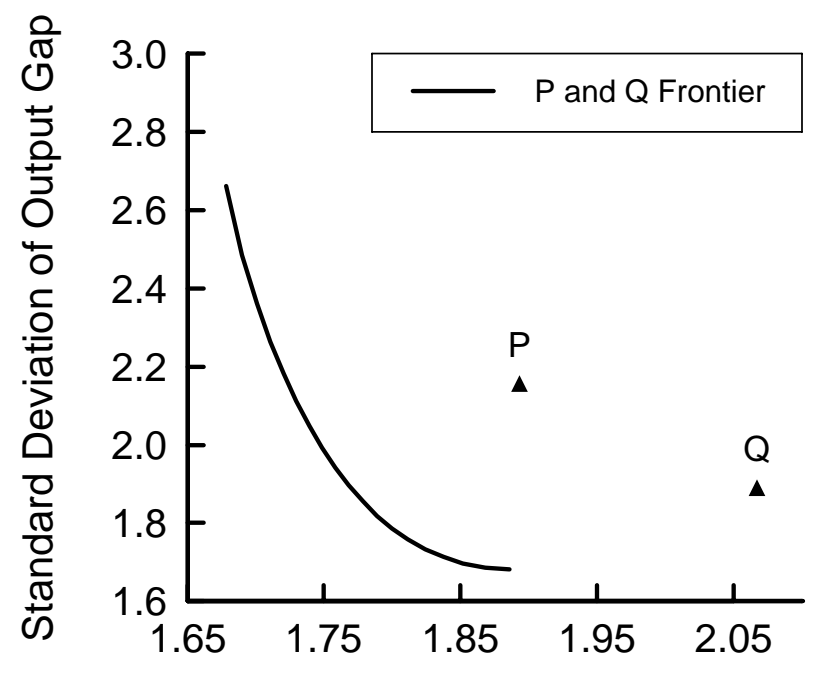

Standard Deviation of Inflation 